\title{
Household Debt and Monetary Policy: Revealing the Cash-Flow Channel*
}

\author{
Martin Flodén \\ Sveriges Riksbank and CEPR \\ Jósef Sigurdsson \\ IIES, Stockholm University \\ Matilda Kilström \\ Stockholm University \\ Roine Vestman \\ Stockholm University and SHoF
}

June 1, 2016

[First draft. Comments welcome.]

\begin{abstract}
We study the effect of monetary policy on spending when households hold debt with variable interest rates. When interest rates on outstanding loans vary with the short-term market interest rate, monetary policy has a direct and immediate effect on households' expenses and disposable income. If households are borrowing constrained, they will respond to a shock to disposable income by adjusting their spending. As a result, a monetary policy-induced interest rate change leads to a larger change in consumption than what is predicted by the elasticity of intertemporal substitution. We examine this cash-flow channel of monetary policy using administrative data on Swedish households. We estimate a strong and statistically significant response in spending to changes in interest expenses. More specifically, we estimate a marginal propensity to consume (including durable consumption) that is around unity or even higher in response to monetary-policy induced changes in interest expenses. For example, highly indebted households with adjustable rate mortgages reduce consumption growth by several percentage points more in response to a one percentage point increase in the household interest rate than households with little debt or fixed rate mortgages. Our findings imply that monetary policy will have a stronger effect on real economic activity when households are highly indebted and have adjustable rate mortgages.
\end{abstract}

JEL classification: D14, E21, E52, G11

Keywords: Monetary policy, consumption, household debt, variable interest rates, adjustable rate mortgages

*An earlier version of this paper was presented under the title "Household Consumption, Debt and Interest Rate Payments". We thank Tobias Broer, Per Krusell, Kurt Mitman, Kathrin Schlafmann, and seminar participants at IIES, Stockholm University, and Sveriges Riksbank for valuable comments and helpful discussions. 


\section{Introduction}

A fundamental question in macroeconomics is to which degree and via which mechanisms monetary policy can affect the real economy. Although being a widely studied area, there remains limited consensus about exactly how monetary policy exerts its influence. A subtler question is whether households are unequally affected by monetary policy. In this paper we study how monetary policy can differentially affect household consumption by directly affecting the disposable income of households that hold loans with interest rates that vary with the short-term market interest rate.

In standard macroeconomic models with nominal rigidities, such as the contemporaneous New Keynesian paradigm, the primary mechanism through which monetary policy operates is the interest rate channel. Because of rigid nominal wages and prices, an increase in the nominal interest rate is not fully and instantaneously reflected in changes in expected inflation, and therefore translates into an increase in the real interest rate and the user cost of capital. According to the Euler equation, an increase in the real interest rate raises households' value of future consumption relative to current consumption, leading to postponement in consumption and private investment. Although this mechanism is the one which is at the heart of the textbook macroeconomic models, many researchers, e.g. Bernanke \& Gertler (1995), have found that changes in monetary policy have a more powerful effect on the real economy than predicted by conventional estimates of the intertemporal interest rate elasticities of consumption and investment. This observation implies the existence of other important transmission mechanisms than the standard interest rate channel. Among other channels that have been studied extensively are the wealth channel (Ando \& Modigliani, 1963) and the credit channel (Bernanke \& Gertler, 1989).

In modern economies, where a large share of households hold debt, monetary policy can also have a direct effect on household spending via its effects on households' cash flows and disposable income. For example, a tightening of monetary policy raises interest rate expenses for households with adjustable mortgage rates and therefore has a negative impact on disposable income of such households. If the household is forward-looking and has good access to financial markets, such variations in cash flows need not result in consumption responses. But if for some reason the household cannot or does not want to increase its debt in response to temporarily lower disposable income, monetary policy will affect consumption also through this cash-flow channel. ${ }^{1}$

One would suspect that the importance and effectiveness of this channel depends on a number of factors such as how wealth and debt is distributed across households, how the marginal propensity to consume out of disposable income varies between savers and borrowers, and how elastic market interest rates are to changes in monetary policy. In particular, institutional details in the mortgage market matter. If the market is dominated by fixed-rate mortgages (FRMs), as in the United States, Germany, and France, one would expect the cash-flow channel to be muted. But in economies where most mortgages have an adjustable rate (ARMs), as in the United Kingdom,

\footnotetext{
${ }^{1}$ This terminology has previously been used by for example Cloyne et al. (2015) whereas Berben et al. (2004) and Di Maggio et al. (2014) refer to the same channel as the "income channel".
} 
Spain, and Sweden, the cash-flow channel may be important for the transmission of monetary policy. However, to date there remains limited evidence on how households are influenced through this channel.

In this paper we estimate the marginal propensity to consume out of a change in interest expenses. We study these effects using household data from Sweden, where adjustable rate mortgages is a standard, non-exotic, product. A common challenge in most previous empirical studies on the impact of unearned income on consumption is lack of datasets that feature both a high quality measure of consumption and data on households' wealth and balance sheets. We overcome this problem by using administrative panel data based on tax reports, which allows us to impute a measure of consumption as well as providing us with detailed information on all earnings, income, assets and debt positions.

A typical identification problem when trying to estimate the impact of monetary policy is that changes in monetary policy are endogenous to the economic development. It is therefore difficult to identify the causality from monetary policy to economic outcomes. Such problems are mitigated with the household-level data that we use. All households are affected by the same monetary policy, but the impact varies from household to household because they have different balance sheets and financial contracts. In particular, we examine how monetary policy affects consumption choices for households with large debt positions and ARMs relative to households with less smaller debt positions and FRMs. Most of indebted Swedish homeowners have at least a share of their mortgages with adjustable interest rates (Holmberg et al. , 2015). A possible concern is that households may select into adjustable vs. fixed interest rates based on household-specific characteristics that are correlated with macroeconomic developments. ${ }^{2}$

To some extent, such problems are mitigated by our panel structure which allows us to control for household fixed effects in addition to observables such as income, age, and wealth. More importantly, the choice between adjustable and flexible rates in Sweden does not seem to be driven by endogenous selection. One indication of this is that households that we identify as having variable rates in our sample have observable characteristics very similar to households identified as having fixed rates. Moreover, a recent study on Swedish households by Holmberg et al. (2015), which has access to precise details in the mortgage contracts and to the banks' assessment of household default probabilities, does not find that the default probability correlates with the choice of interest-rate fixation.

We are thus able to study how households that are more likely to be credit constrained and have a higher degree of variability in their mortgage interest rates respond to interest rate changes

\footnotetext{
${ }^{2}$ In general, it is not possible to characterize an optimal mortgage contract. Rather, Cocco (2013) points out the benefits of offering households a menu of contracts. Campbell \& Cocco (2003) study the selection between ARMs and FRMs in a life-cycle model with risky labor income and borrowing constraints. Their results suggest that households with a large mortgage, risky labor income, high risk aversion, a high cost of default, and a low probability of moving are less likely to prefer an ARM. Further, Campbell \& Cocco (2015) show, in an incomplete markets model, that ARMs have a higher default rate than FRMs when interest rates increase. Badarinza et al. (2015) study the determinants of within- and cross-country variation in the ARM share. They find evidence suggesting that households consider both current interest costs, consistent with borrowing constraints, as well as life-time cost minimization.
} 
induced by monetary policy. Figure 1 previews our main finding. The figure plots the percentage point change in the policy interest rate over our sample period. It also plots median consumption growth of all homeowners minus median consumption growth of highly indebted homeowners with ARMs. The figure shows that this difference co-moves with the repo rate. That is, an increase in the policy interest rate has a smaller impact on consumption growth for the median homeowner than for homeowners who are exposed to the interest rate change. ${ }^{3}$ Our analysis deepens this insight. We sort and split the sample of households with positive debt in three equally large groups based on debt-to-income (DTI) ratios. We show that the consumption response is the strongest for households with a medium and high DTI and adjustable rate mortgages. For a fully adjustable mortgage, a one percentage point increase in the household interest rate reduces consumption growth by 4 to 5 percentage points for homeowners with high debt (a DTI ratio around 280 percent).

Our paper contributes to several strands of literature. Many of the previous empirical studies on the effect of monetary policy on households' economic activity analyze aggregate data. Our key contribution is to a recent literature that studies the effects of monetary policy at the micro level. Di Maggio et al. (2014) study consumption and deleveraging decisions of households prior to, and following, a change in their monthly interest payments. They study data for the subsample of US households with non-agency mortgages which have interest rates that remain fixed for 5 years but are then automatically adjusted. Differences in the timing of these adjustments allow for difference-in-difference estimation. The authors find strong responses in consumption to a change in interest expenses. At the reset date, monthly interest payments drop by about a half, causing a substantial increase in car purchases, the authors' main measure of consumption. In addition, they find that a share of the increase in disposable income generated by lower expenses is devoted to saving through deleveraging on the mortgage. Applying a similar identification strategy, Keys et al. (2014) study proprietary loan data and estimate the balance sheet effects of a change in interest payments following the reset date. They find that a reduction in mortgage payments causes a decrease in defaults, a drop in credit card debt, and an increase in new auto debt, indicating an increase in durable consumption. Cloyne et al. (2015) study the response of expenditure and income to monetary policy in the UK, where, as in Sweden, ARMs make up a large share of mortgages. Due to lack of data on household debt positions, the authors analyze responses for three groups of households based on their housing market status: outright home-owners, mortgagors, and renters. They find that an unanticipated increase in the interest rate leads to a large and significant drop in mortgagors' expenditures which is more pronounced in purchases of durable goods. Outright homeowners show no significant response. Additionally, they find that monetary policy shocks lead to variations in house prices and loan sizes, which are of a similar magnitude. Somewhat surprisingly, however, income changes for the different tenure cohorts are not significantly different from each other, even when accounting for the effect of interest rates on interest expenses.

\footnotetext{
${ }^{3}$ The exception from this pattern is 2002, when the repo rate was slightly higher than in 2001 (less than 0.1 percentage points higher) but when consumption growth was slightly higher for the highly indebted group of households with ARMs.
} 
In line with these studies, we find that monetary policy affects household consumption decisions through cash-flow effects that operate outside the normal interest-rate channel.

We also contribute to the general literature studying the transmission mechanisms of monetary policy (see e.g. Bernanke \& Gertler, 1995; Kashyap \& Stein, 2000) and, in particular, to the literature on the relation between household debt and the transmission mechanisms of monetary policy. Calza et al. (2013) document that the transmission of monetary policy shocks to residential investment and house prices is stronger in countries with more flexible and developed mortgage markets, and that responses in consumption are stronger in countries where there is higher prevalence of ARMs. Rubio (2011) builds a New Keynesian model with a housing market and collateral-constrained households, extending the framework in Iacoviello (2005) by allowing for both adjustable and fixed rate mortgages. Monetary policy has a stronger effect when a larger share of mortgages have adjustable rates. However, in general equilibrium the partial equilibrium effects are muted by a redistribution between borrowers and savers as well as by labor supply responses. In a recent paper, Garriga et al. (2015) view mortgages with contract frictions that prevent interest rates to adjust instantly as a nominal rigidity which they incorporate into a general equilibrium model as the only source of nominal friction. The authors find that monetary policy shocks have larger real effects under ARMs than FRMs since not only does an increase in the nominal interest rate reduce consumption growth through a reduction in new borrowing but also by increasing (real) mortgage payments.

The long period with extraordinarily expansionary monetary policy after the outbreak of the financial crisis has resulted in a discussion about the distributional impact of monetary policy (see for example Bullard, 2014; Mersch, 2014; Bernanke, 2015). By estimating disaggregated household reactions to monetary policy, our paper contributes to the recent literature that analyzes this distributional impact. In previous theoretical work, Garriga et al. (2015) find that monetary policy shocks redistribute income from homeowners to capital owners under ARMs, but vice versa under FRMs. Auclert (2015) develops a model to evaluate the redistributional effect of monetary policy on consumption. The model provides two important predictions. First, if all mortgages in the US where ARMs, the effect of interest-rate changes on consumer spending would more than double. Second, this is an asymmetric effect, with interest rate increases reducing consumption more that interest rate cuts would raise it. ${ }^{4}$ Another recent contribution is Greenwald (2016), who shows that inclusion of a payment-to-income constraint in a DSGE model generates substantial aggregate effects.

Our study is also related to a series of papers studying household consumption responses to shocks to unearned income and fiscal stimulus programs. Shapiro \& Slemrod (2003), Johnson et al. (2006), Agarwal et al. (2007), Shapiro \& Slemrod (2009), and Parker et al. (2013) study the effect of 2001 and 2008 economic stimulus payments in the US on consumer spending. ${ }^{5}$ Agarwal \&

\footnotetext{
${ }^{4}$ For recent empirical studies on the redistribution channel of monetary policy, see, e.g., Sterk \& Tenreyro (2015) and Casiraghi et al. (2016).

${ }^{5}$ For studies on the consumption responses to other sources of shocks to disposable income, see, e.g. Stephens (2008), Kueng (2015), and Hsieh (2003).
} 
Qian (2014) study the effect of a one-time cash payout from the Singaporean government which, in contrast to the US stimulus payments, were unanticipated by Singaporean households. In all cases, the authors find a considerable consumption response to these income shocks. And the response is stronger for those that are more likely to be liquidity constrained, e.g. have low liquid assets or a low credit card limit. These papers study consumption responses to a positive shock to disposable income as a result of fiscal policy programs. One way to view our paper is as a monetary policy analogue to the fiscal policy programs studied in this literature.

Lastly, we contribute to a literature that studies whether sensitivity of household spending to changes in income is related to mortgage debt or house prices. Mian et al. (2013) study household consumption response to large negative shocks to household wealth, finding that households with different levels of wealth have a different marginal propensity to consume out of a dollar lost. Baker (2014) finds that the consumption elasticity of income is significantly higher in households with high debt. This relation is not causal, however, since level of liquid assets and access to credit drive most of the heterogeneity in consumption responses to an income shocks and debt by itself plays a minor role. Using Danish administrative data, Andersen et al. (2015) study if household leverage prior to the financial crisis amplified the reduction in household spending during the crisis. They find a negative correlation between pre-crisis debt growth and consumption growth during the crisis but no relation between high debt at the time of the crisis and a spending decline over the course of the crisis. ${ }^{6}$

The remainder of this paper proceeds as follows. Section 2 provides details on the dataset we use and our measure of consumption as well as presenting general summary statistics. Section 3 presents empirical and theoretical motivation as well as a discussion of the empirical strategy. We present our main findings in Section 4, while Section 5 provides a sensitivity analysis. Section 6 concludes.

\section{Data and Summary Statistics}

Data description The main dataset we use is the Swedish registry-based panel dataset LINDA (Longitudinal INdividual DAta for Sweden). This dataset is representative for the Swedish population, covering a random sample of 300,000 households and their members. Since in Sweden, as in other Scandinavian countries, each tax payer has a unique social security number, we are able to construct a panel using several sources of administrative data. Our sample period covers 20002007. During this period, Sweden levied a wealth tax which meant that taxpayers were required to provide the tax authority with comprehensive information on all taxable wealth, in addition to information on earnings and income. The tax registers therefore include information about all taxable income and transfers, tax payments, liabilities and taxable wealth, including value of real estate (i.e., houses, apartments and cabins), cash holdings on bank accounts, bonds, stocks, and

\footnotetext{
${ }^{6}$ The paper by Andersen et al. (2015) is relevant for out study also because they use a similar dataset and, as we, impute consumption from changes in households' balance sheets.
} 
mutual funds. ${ }^{7}$ Values of real estate are the tax-based values for houses and cabins, which are a function of a long list of characteristics of the property and updated yearly using a price index which is constructed from transactions in a given municipality in each year. Values of financial assets are detailed and, for instance, each household reports each and every listed stock or mutual fund it holds in its tax filings. The dataset contains information on total household debt which is the debt measure we use in the empirical analysis. ${ }^{8}$ In addition, the dataset includes residential location for each household and various demographic variables.

Imputing consumption We use this detailed dataset to impute a measure of consumption based on the approach in Koijen et al. (2015). This is a vital part of our exercise since the main outcome of interest is spending. Although our data is reported at the individual level, we construct the measure of consumption for the household. Information for the individual tax payer is aggregated to the household level using marital status, residential location, and parent-child linkages. Household characteristics, such as age and education, represent a household head, which we take as the oldest individual in the household unless more than one individual is of that same age, in which case we choose the oldest male.

A common way of describing a given household $i$ 's budget constraint in year $t$ is as follows

$$
C_{i, t}=Y_{i, t}+\Delta D_{i, t}-r_{i, t}^{D} D_{i, t-1}-\Delta A_{i, t}+r_{i, t}^{A} A_{i, t-1}
$$

That is, consumption, $C$, is constrained by disposable income, $Y$, the change in outstanding debt, $\Delta D$, interest payments, $r^{D} D$, savings, $\Delta A$, and their returns $r^{A} A$. Based on the notion that the budget constraint can serve as an accounting identity in a given year, it can be used to impute a measure of consumption as total income net of change in wealth from previous period. This is possible since all terms on the right-hand side of equation (1) are observable in our data. Mapping equation (1) into the detailed structure of our data gives the identity

$$
c_{i, t}=y_{i, t}+\Delta d_{i, t}-r_{i, t}^{d} d_{i, t-1}-\Delta b_{i, t}-\Delta v_{i, t}-\Delta h_{i, t}-\Delta \psi_{i, t}-\omega_{i, t}
$$

where the household's disposable income, $y_{i}$, includes labor income, transfers and benefits (all net of taxes), and financial income, $\Delta d$ is the change in debt, $r^{d} d$ are interest payments, $\Delta b$ is the change in deposits on bank accounts, $\Delta v$ is active re-balancing of mutual funds, stocks, and bonds, $\Delta h$ is the change in housing wealth (due to buying/selling), $\Delta \psi$ are changes in capital insurance accounts, and $\omega$ are contributions to private pension savings.

Equation (2) is identical to the imputation method of Koijen et al. (2015), who show that the correlation between the imputed measure and a survey-based measure of consumption exceeds 0.5 at the household level. Relative to Koijen et al. (2015), one refinement has been made which

\footnotetext{
${ }^{7}$ For further details on the dataset used in the current paper see Koijen et al. (2015), and see Edin \& Fredriksson (2000) for a detailed account of the data collection process for LINDA.

${ }^{8}$ We are unable to separate household debt into mortgages and other components. However, given that our main sample consists of homeowners, the main share of household debt will likely consist of mortgage debt.
} 
concerns bank accounts. Bank account deposits are only reported if certain criteria are met and those changed in 2006. In 2000-2005, a deposit in a bank account was reported in the Swedish tax records if the earned interest from that account exceeded SEK 100, while in 2006 and 2007 the deposit was only reported if the balance on the account exceeded SEK 10,000. Overall, the new rule implies an improvement in accuracy. However, to avoid over-stating savings between 2005 and 2006 we artificially implement the reporting rule of 2000-2005 also on the latter period when imputing consumption.

Sampling restrictions We restrict the sample in four ways. First, we restrict the households in our sample to be represented by a household head which is 18 years or older. Second, since changes in the family structure, such as divorces, may affect our consumption measure, we exclude observations for unstable households, i.e. when the household head is not the same as in previous period. Third, we exclude observations for those years when households buy or sell residential housing. The reason for this restriction is that we have an imperfect measure of the value of the real estate, and changes in this variable - which is undoubtedly the largest component in households' asset portfolio - might bias our consumption measure. Fourth, we restrict our attention to households that remain in our panel for 3 or more years. The main reason for this restriction is, as we explain further in Section 3, to be able to compute the correlation between each household's interest rate and the monetary policy rate, which is our measure of fixed and adjustable rate loans.

We exclude outliers in our sample in four ways. First, we exclude observations when our consumption measure is negative. Negative consumption is likely to reflect some measurement issues that we are unable to account for in the consumption imputation process. Second, we exclude the bottom 2.5th percentile in the income distribution. Third, we exclude the top 2.5th percentiles of the distribution of household specific interest rates. Fourth, we exclude the bottom and top 5 th percentiles of the distribution of consumption growth rates. These restrictions leave us with a sample of around 50,000 households on average per year, of which about 30,000 per year are homeowners. The latter group is of our main focus since those holding mortgages have interest expenses that may be affected by monetary policy.

Summary statistics We now report summary statistics for the main variables in our dataset. As we highlight in the following section, an important part of our analysis is to identify groups of households that (i) are likely or unlikely to be credit constrained, and (ii) have interest expenses that are either sensitive or insensitive to changes to monetary policy shocks. Therefore, we split the sample along two dimensions and present summary statistics by groups. First, as we do in our main analysis, we split the sample by renters and four groups of homeowners by debt-to-income (DTI) ratios, our primary measure of (in)ability to smooth shocks to interest expenses. Second, we split the sample by variability of interest rates, measured by correlations between householdspecific interest rates and the repo rate.

Table 1 reports summary statistics for the full sample, renters, and four groups based on DTI 
ratios, where the sample split is based on the previous year's DTI distribution. ${ }^{9}$ We report all monetary values in Swedish kronor (SEK).${ }^{10}$ On average, homeowners without debt have fewer household members, are substantially older, have less income and consumption, but more financial assets than the three groups with positive debt, which are more homogeneous along these dimensions. Differences in DTI ratios across the three groups with non-zero debt mostly represent differences in indebtedness between the groups rather than differences in income or value of real estate, since disposable income and loan-to-value (LTV) ratios do not display stark differences. Renters on average have relatively low consumption, income, debt and financial assets. However, and as expected, they do not differ a lot from the other groups in terms of interest rates and the correlation measure.

In Table 2 we report summary statistics for households based on if their interest rate has a correlation with the repo rate below (low variability) or above (high variability) the median correlation. Although this split of the sample represents households with very different mortgages, the sample seems balanced along this dimension. The two groups have similar wealth (both financial assets and real estate), income, and consumption. Importantly, they do not show stark differences in indebtedness and DTI ratios. The table also reports results from a statistical test of these differences. Column three reports the coefficient estimates from a single-variable regressions of each characteristic on an indicator of having a high variable interest rate. The coefficients are statistically significant apart from a few exceptions. However, considering the magnitude of the coefficients there are limited economically significant differences in balance sheet positions and household characteristics across the two groups.

Before moving on to our empirical analysis, we graphically summarize important patterns in our data in Figures 2-6. In our empirical strategy we will then build on implications from these patterns. Panel (a) in Figure 2 shows that disposable income and consumption are somewhat higher for households with higher DTI ratios. As indicated by Table 1, much of that difference is explained by such households being larger than households with less debt. As one would expect, renters on average have considerably less debt than indebted homeowners. Looking explicitly at interest expenses, in panel (b) of Figure 2, we note that the most indebted homeowners not only have the highest interest expenses in absolute terms, since this group has most debt, but also measured relative to their disposable income.

Our empirical analysis builds on the hypothesis that households with higher DTI are more sensitive to interest rate changes than less indebted households. One potential caveat to this hypothesis is that households that are more indebted according to this measure are also more wealthy and therefore more able to respond to unexpected expenses. To assess this possibility Figure 3 considers the asset side of households' balance sheets. Two features are apparent. First, we note that households with a high DTI ratio hold on average more illiquid assets than other households. This is easily understood by noting that much of the debt held by these households

\footnotetext{
${ }^{9}$ We treat those with zero debt, or no available correlation measure, as a separate group, and split the sample of indebted homeowners in three groups based on the DTI distribution.

${ }^{10}$ During our sample period the average exchange rate to the U.S. dollar was about 8 SEK/USD.
} 
are mortgages used to finance their housing investment that makes up a large share of their stock of illiquid assets. Second, for liquid assets - defined as all financial assets less pension holdings - this pattern is reversed. Kaplan et al. (2014) show the importance of considering the varying liquidity of household assets. They emphasize the significant share of "wealthy-hand-to-mouth" households. These households are wealthy in terms of illiquid wealth but hold very little liquid wealth. Importantly, these wealthy households have a large propensity to consume out of changes in transitory income and do not react strongly to news about future income changes. In this light the pattern we observe in the raw data strengthens our hypothesis of the sensitivity of indebted households to changes in interest expenses.

Figures 4 and 5 provide further illustration of these patterns by documenting how debt and asset holdings vary across the income distribution. High-income households are more indebted, both measured by DTI and the loan-to-value (LTV) ratios, than low-income households. The DTI ratio rises gradually with income and so does the LTV ratio, although more modestly. These figures also document that households hold very limited liquid assets, both relative to their income and to their illiquid asset holdings. Furthermore, although all households hold little liquid assets, high-income households hold least liquid assets, both relative to their income and to their illiquid assets.

To gauge at whether there are other important differences in indebtedness and wealthiness than emphasized above, Figure 6 documents DTI, liquid assets-to-income, and LTV ratios by age groups and geographical areas. As expected, young and middle-aged households have more debt than older households, and the oldest group also has more liquid assets. There is limited geographical variation, although households outside of the three large city regions have somewhat higher debt relative to house values.

To summarize, these figures document that although high-income households are wealthy in terms of illiquid wealth they hold low levels of liquid assets, are highly indebted and have high interest expenses relative to their income. When faced with increased expenses, such as after a sudden increase in their mortgage interest rate, these households will face a difficulty in retaining their level of consumption unless being able to access additional credit. If credit constrained, these households are likely to have to reduce their level of consumption when faced with increased expenses.

\section{Empirical Framework}

Theoretical motivation To motivate our empirical framework we briefly consider potential models of consumer behavior. A natural starting point for studying consumption and savings decisions are the aforementioned life cycle/permanent income models. In these types of models consumers have concave preferences which induces a consumption smoothing motive. This im-

plies that, for unconstrained households that are forward-looking and maximize expected utility, consumption will only react to unanticipated income changes. In the most extreme setup, where markets are complete and allow households to fully insure against idiosyncratic risks, the con- 
sumption growth rate will be identical for all households. The first-order conditions for household optimization then reduce to

$$
\Delta \log c_{i, t}=\lambda_{t}
$$

where $\lambda_{t}$ captures anticipated and unanticipated macroeconomic developments that are common to all households. ${ }^{11}$ A somewhat more general specification that does not rely on full insurance between households results in the first-order condition

$$
\Delta \log c_{i, t}=\lambda_{t}+\varepsilon_{i, t}
$$

where $\varepsilon_{i, t}$ contains news on idiosyncratic consumption possibilities for the household. According to these theories, a change in monetary policy will be captured by the term $\lambda_{t}$ and therefore have an identical impact on consumption growth for all households. But it is well-established that there is little empirical support for a strict interpretation of the theories behind equations (3) and (4). For example, researchers have found that consumption, in violation of equation (4), often responds to predictable household-specific income changes. One suggested remedy to explain such behavior is to introduce borrowing constraints. Carroll \& Kimball (1990) is an early theoretical contribution showing that the average marginal propensity to consume increases in the presence of borrowing constraints and uncertainty. Campbell \& Mankiw (1990) introduce "rule-of-thumb" consumers as another potential explanation for the excess sensitivity of consumption. More recently, as discussed in Section 1, studies such as Mian et al. (2013) show that heterogeneity in the marginal propensity to consume depends on household balance sheet compositions such as their wealth and liquid assets.

If binding borrowing constraints or hand-to-mouth behavior due to other factors are prevalent in the economy, interest-rate changes will tend to affect consumption growth more for some households than others. To motivate an empirical specification that allows for such cash-flow effects, consider a hand-to-mouth household that for some reason lets marginal changes in disposable income feed directly into consumption. If the household holds assets and debt constant, the budget constraint (2) implies that

$$
\Delta c_{i, t}=\Delta y_{i, t}-d_{i, t-1} \Delta r_{i, t}^{d}
$$

After log-linearizing, this can be approximated as

$$
\Delta \log c_{i, t}=\alpha_{i} \Delta \log y_{i, t}-\alpha_{i} D T I_{i, t-1} \Delta r_{i, t}^{d}
$$

where $\alpha_{i}$ is the inverse of the consumption-to-income share for household $i$ and DTI is the debtto-income ratio. If cash-flow effects work through binding borrowing constraints that are updated period-by-period, households may respond even more strongly to news. In particular, if there are

\footnotetext{
${ }^{11}$ Although not explicitly captured in this specification, preference shifters, such as age or household composition, may then still generate variation in consumption growth between households.
} 
binding debt-to-income restrictions households may respond more strongly to income news than indicated by (6), and if there are binding loan-to-value restrictions households may respond also to changes in house prices.

Empirical strategy Our empirical strategy aims at estimating the extent to which the cash-flow channel of monetary policy generates a heterogeneous effect on household consumption growth. If these cash-flow effects of monetary policy have an impact on household behavior, that impact is likely to be most visible for households with adjustable rate mortgages and high debt. As mentioned above, we cannot directly observe in our dataset if a household has a fixed or adjustable rate mortgage. Instead we classify indebted homeowners as having a high ("ARM") or low ("FRM") variability of their interest rates based on if the correlation of their interest payments with the repo rate is above or below the median correlation in the sample. In order to test our hypothesis that constrained households are more sensitive to interest rate changes, regressions are estimated on three groups depending on their indebtedness. That is, homeowners with non-zero debt are split into three groups by their level of DTI (groups Low, Medium and High in Table 1). ${ }^{12}$ We also consider renters as a separate group. Our main empirical specification estimates the following regression equation

$$
\Delta \log c_{i, t}=\beta_{0}+\beta_{1} \Delta r_{i, t}^{d}+\beta_{2} D T I_{i, t-1}+\beta_{3} \mathbf{X}_{i, t}+\beta_{4} \delta_{t}+\varepsilon_{i, t}
$$

where $\Delta r_{i, t}^{d}$ is the change in the household-specific interest rate, described in detail below, and $D T I_{i, t-1}$ is the DTI ratio in the previous year. $\mathbf{X}_{\mathbf{i}, \mathbf{t}}$ is a vector of controls consisting of various factors influencing preferences for consumption. We include in this vector a fourth order polynomial in age, education, household size and the change in household size. $\delta_{t}$ includes a full set of year fixed effects.

Our attention is on the implications of cash-flow effects of interest-rate changes, and hence on the parameter $\beta_{1}$. The empirical specification in (7) is intended to capture the most important theoretical implications from the previous subsection. If markets are complete as in (3), all effects of interest-rate changes on household consumption are captured by the year fixed effects. We then expect $\beta_{1}=0$ for all households. ${ }^{13}$ If households cannot insure against idiosyncratic risks, as in (4), $\Delta r_{i, t}^{d}$ should only affect household consumption growth if the interest-rate change is correlated with household-specific news. Therefore, as we substantiate below, we use an instrumental variable approach in order to remove the effect of the idiosyncratic component of the interest rate. In those cases, the implication of (4) is again that $\beta_{1}=0$ for all households.

But if some households are borrowing constrained, we expect the cash-flow effects from $\Delta r_{i, t}^{d}$

\footnotetext{
${ }^{12}$ In the sensitivity analysis we extend the analysis by presenting results based on net Debt-to-Income and Loan-toValue groups.

${ }^{13}$ In several empirical specifications we estimate separate regressions for different groups of households in the sample. In those cases we allow for group-specific year fixed effects and thereby make this argument less relevant. The argument is most relevant for the estimates reported in the first two columns of Table 11 and for the sensitivity analysis reported in Tables 16-18
} 
to affect consumption. More specifically, for a constrained household that consumes all its disposable income, (6) implies that $\beta_{1}=-\alpha_{i} D T I_{i}$, i.e. proportional to the household's debt-to-income ratio. By splitting the sample into groups depending on their debt-to-income position, we attempt to capture households that are more or less likely to be borrowing constrained. ${ }^{14}$ Our underlying assumption is thus that highly indebted households are more likely to be constrained. If that is the case, there are two reasons for why we expect the absolute value of $\beta_{1}$ to be higher in highDTI groups: first because there is a larger fraction of hand-to-mouth households in those groups than in low-DTI groups, and second because hand-to-mouth households according to (6) are more affected by interest-rate changes when they have high DTI. ${ }^{15}$

Our proposed transmission channel for monetary policy relies on a high prevalence of adjustable interest rates. Figure 7 shows the division of fixed-rate periods of new mortgages in Sweden during the relevant period. Adjustable rate mortgages are defined as mortgages with a fixed-rate period of three months or shorter. It is clear that a nontrivial share, approximately fifty per cent, of new mortgages had adjustable rates during the period. Figure 8 reports the division of fixed-rate periods in the stock of outstanding mortgages. The value-weighted share of adjustable rate mortgages increases from 30 to 40 percent during the time period. Taken together, these aggregate statistics suggest that the cash-flow channel may be an important transmission mechanism.

Let us now return to the measurement of household-specific interest rates in our microdata set. We do not observe household debt contract details in our data. However, we observe both interest payments and balance on loans every year. For each household we therefore define the interest rate $r_{i, t}^{d}$ as the total interest expenses divided by total debt in the same period,

$$
r_{i, t}^{d}=\frac{\text { interest payment }_{i, t}}{\operatorname{debt}_{i, t}}
$$

and then construct the change in the household-specific interest rate as $\Delta r_{i, t}^{d}=r_{i, t}^{d}-r_{i, t-1}^{d}$. Figure 9 shows how this interest-rate measure (value-weighted across households) varies with the repo rate over the sample period. This figure highlights the prevalence of adjustable rate loans, with the average household interest rate slightly lagging the policy rate.

Table 3 illustrates how changes in the repo rate affect households' annual interest payments. Column 1 shows that a one-percentage point increase in the repo rate increases interest payments by SEK 410. For the three groups of homeowners, the effects are SEK 638, 1,584, and 3,507, respectively. These are substantial effects but nevertheless consistent with households holding a mix between fixed and variable interest loans when we consider the reported debt levels in table 1. Table 4 repeats the analysis using household-specific interest rates $\left(r_{i, t}^{d}\right)$. Notably, the estimates for the groups Medium and High are much higher and consistent with the groups' debt levels.

\footnotetext{
${ }^{14}$ Zeldes (1989) is an early study that estimates Euler equations and splits the sample into groups that are more or less likely to be borrowing constrained.

${ }^{15}$ Based on the theoretical discussion above, there are some alternative ways to formulate the regression equation to capture how the cash-flow effects interacts with the households indebtedness, and one may argue that other control variables should be included. We return to such issues in section 5.
} 
The effect of a one percentage point change in the repo rate on interest payments is about half the effect of a one percentage point increase in the household interest rate for these groups. This indicates that, on average, about half of outstanding loans in our sample have adjustable interest rates, which is in line with the aggregate data. Moreover, the transmission of the policy rate into interest expenses is about the same for all of the three groups of homeowners. We conclude that the high prevalence of adjustable rate mortgages in the aggregate statistics is reflected in our household-specific measure of the interest rate.

Identification and instrumental variables As a starting point, $\Delta r_{i, t}^{d}$ is our main explanatory variable. However a potential problem arises if changes in the household-specific interest rate are correlated with household-specific income shocks. For example, a negative income shock may result in lower consumption for a household. Such shocks may in addition induce banks to charge a higher mortgage rate for that household. To mitigate such endogeneity problems, we construct a variable that we either substitute for $\Delta r_{i, t}^{d}$ or use as an instrumental variable. We generate the variable $\Delta \widetilde{r}_{i, t}$ as follows. We first calculate the correlation between household-specific interest rates and the repo rate,

$$
\operatorname{corr}_{i}=\operatorname{corr}\left(\text { repo rate, } r_{i}^{d}\right) \text {. }
$$

Figure 11 shows the density of the household interest rate and the correlation measure in our sample. We see that there is substantial variation both in the household-specific interest rate and in its correlation with the repo rate. We then compute

$$
\Delta \widetilde{r}_{i, t}=\operatorname{corr}_{i} \times \Delta \text { repot }_{t}
$$

This variable $\Delta \widetilde{r}_{i, t}$ therefore measures the intensity of the impact of monetary policy on interest payments at the household level.

For $\Delta \widetilde{r}_{i, t}$ to be a good instrument we require it to be highly correlated with the endogenous regressor. In particular, the repo rate should be highly correlated with the household-specific interest rate for households we classify as having debt with adjustable-rates. This is verified in Figure 10, which provides a graphical documentation of there being a strong "first-stage". We see that the interest rate for households with adjustable-rates co-moves strongly with the repo rate year-by-year, while the interest rate for households with low adjustability is much less sensitive to monetary policy.

In order for this variable to be a valid instrument we also require the exclusion restriction to hold. The instrument consists of two components: the household specific correlation and the change in the repo rate. In Sections 1 and 2 we argue that it is reasonable to assume that there is limited selection on observables into adjustable rate mortgages. The exclusion restriction could, however, be violated if changes in the repo rate are correlated with unobservable factors that have heterogeneous impact on consumption growth across the household groups that we study. We address such concerns in three stages. 
First, we argue that it is unlikely that there are any problematic correlations between the repo rate and group-specific consumption developments. If anything, such a problem would bias our estimate of $\beta_{1}$ downwards in absolute terms. That is, our estimates would be less negative than the true estimates and work against our hypothesis. This is because central banks typically raise the interest rate in response to positive macroeconomic news and because borrowing constraints typically become less binding in response to such news. Such correlations would then tend to result in a positive correlation between the repo rate and consumption of constrained household groups.

Second, in some specifications we include household income changes, $\Delta \log y_{i, t}$, as an explanatory variable. One reason for including income changes in the specification is that they should be included for constrained households according to equation (6). But more importantly, income changes most likely capture much of the household-specific news in the term $\varepsilon_{i, t}$ in equation (4). It is less likely that aggregate interest rate changes remain correlated with new information that remains in $\varepsilon_{i, t}$ after controlling for household-specific income changes. That our results are largely unaffected by the inclusion of this term strengthens our argument that the exclusion restriction is not violated.

Third, in some specifications we use monetary policy shocks as an instrument for interest rate changes. We then calculate monetary policy shocks that summarize the effect of policy surprises on interest rates. Our approach is based on the work in Gertler \& Karadi (2015) where the authors use high frequency identification of monetary policy shocks. This approach is developed to identify exogenous innovations in monetary policy that are due entirely to policy shifts, i.e. innovations that are unrelated to the macroeconomic development. With such an instrument, we address the simultaneity problem which would arise if monetary policy reacts to a macroeconomic development that has a heterogeneous impact on the household groups that we analyze.

To identify this innovation, we use a tight window around the time of a monetary policy announcement to isolate the effect of policy surprise on market interest rates. In Sweden, the monetary policy decision is announced the day after the meeting where the policy rate, the repo rate, is determined. In contrast to Gertler \& Karadi (2015), we do not have access to futures instruments for the full period that we study. We instead use the change in the Treasury bill short term interest rate on the day of the announcement, and assume that the movement in the interest rate that day is dominated by the innovation in monetary policy. More precisely, we construct the monetary policy shock as the difference between the interest rate at the end of the day of the policy announcement and the day before the announcement,

$$
M P S_{d}=i_{d}^{1 M}-i_{d-1}^{1 M}
$$

where $i_{d}^{1 M}$ is the interest rate on the 1-month Swedish Treasury bill and $d$ is the day of a monetary policy announcement. We time aggregate the monetary policy shocks to an annual measure by summing them year-by-year. Figure 12 shows that the resulting monetary policy shocks have a similar development as the repo rate, but that the magnitude of these innovations is considerably 
smaller than the repo rate changes. Using this measure of monetary policy shocks we construct an instrumental variable in similar fashion as before by interaction with the correlation, or sensitivity, measure

$$
\widetilde{M P S}_{i, t}=\operatorname{corr}_{i} \times M P S_{t}
$$

Measurement error Just as any data on household consumption, our data suffer from measurement error. Just to give two examples, sales of expensive art or transfers from parents, leading to additional financial savings in some form, both count mechanically as a reduction in consumption. In addition, as discussed in the previous section, there is a measurement problem in the imputed consumption measure due to small bank deposits not being reported. For all these reasons, we measure

$$
\hat{c}_{i, t}=c_{i, t}+\psi_{i, t}
$$

instead of $c$, where $\psi$ is a measurement error. The problem is that this measurement error can be correlated with our main explanatory variable. To see this, consider an interest rate increase. In response to the higher interest payments, the household can reduce its consumption or draw down on its bank deposits (or possibly on some other asset holdings that we measure without error). If it chooses to draw down on its bank deposits, but we do not measure this, we will instead incorrectly measure that as a reduction in the imputed consumption measure. That is, there will be a negative correlation between $\psi$ and interest rate changes. As a consequence, we will then estimate

$$
\hat{\beta}_{1}=\frac{\operatorname{Cov}\left(\Delta \log \hat{c}_{i, t}, \Delta r_{i, t}^{d}\right)}{\operatorname{Var}\left(\Delta r_{i, t}^{d}\right)}=\beta_{1}+\frac{\operatorname{Cov}\left(\frac{\psi_{i, t}}{c_{i, t}}, \Delta r_{i, t}^{d}\right)}{\operatorname{Var}\left(\Delta r_{i, t}^{d}\right)}
$$

resulting in downward biased estimates of $\beta_{1}$. Such a bias would tend to exaggerate the cash-flow effect that we try to identify.

The reason why we believe that this measurement problem is of limited magnitude is that there is a quantitative limit to the magnitude of $\psi$ (at least per bank account held by the household). Further, we see from the the analysis above that the bias is likely to be small, and smaller as the household income is higher.

\section{Results}

Estimation results using the household interest rates As a starting point we ignore the identification issues discussed above and estimate equation (7) by regressing the consumption growth rate on the change in the household interest rate, $\Delta r_{i, t}^{d}$, as the main explanatory variable of interest. Results are reported in Table 5. Results are presented for renters and by groups of households 
with low, medium, and high levels of DTI. In all of our regressions we control for household characteristics by including a fourth polynomial in age of the household head, household size, and growth in household size. In addition we report estimates that include household fixed effects, which control for all unobservable household characteristics that are constant over time. In all estimations we also include a full set of year fixed effects in order to soak up the effect of year-toyear changes in the macroeconomic environment, including monetary policy, which commonly affect the consumption of all households.

The response of homeowners to interest-rate changes is strong, statistically significant, and increases monotonically with indebtedness. In comparison, renters display the weakest consumption response. We estimate that a one percentage point increase in the household interest rate for a household in the low DTI group with a fully adjustable interest rate reduces consumption growth by 2.4 percentage points, compared to a reduction of 7.9 percentage points for the high DTI group. Including household fixed effects slightly lowers the point estimates, but the difference in the response between low and high DTI households remains similar.

The magnitude of these results is arguably unrealistically high. For example, the average debtto-income ratio in the high DTI group is 2.82 while the average consumption-to-income ratio is 0.94. Based on those values, equation (6) implies $\beta_{1}=-3$ if all households in that group behave as hand-to-mouth consumers, i.e. if they have a marginal propensity to consume (MPC) equal to unity. ${ }^{16}$ For the low and middle DTI groups, the corresponding calculations imply $\beta_{1}=-0.6$ and $\beta_{1}=-1.5$, respectively. The estimates reported in Table 5 thus indicate that the MPC is well above unity for all household groups. One explanation for the large effects that we estimate can be, as discussed above, that the household-specific interest rate increases when the credit-worthiness of the household deteriorates, and that such a deterioration tends to coincide with developments that force the household to reduce consumption. To avoid such endogeneity problems, we now turn to our preferred empirical specification.

Reduced form and IV estimation results using the repo rate To address the potential issue of endogeneity in the changes of household interest rates we now estimate our baseline specification, described in equation (7), using $\Delta \widetilde{r}_{i, t}$ in stead of $\Delta r_{i, t}^{d}$. Recall that $\Delta \widetilde{r}_{i, t}$ measures the intensity of the impact of monetary policy on interest payments at the household level. A reduced form estimation of $\Delta \widetilde{r}_{i, t}$ on consumption growth therefore provides an estimate of how household consumption responds to monetary policy as it operates through the cash-flow channel. The reduced form estimates are reported in Table 6. As before, we find that the consumption response to interest-rate changes increases monotonically with indebtedness of homeowners. The magnitude of these responses is now smaller than before, in particular when household fixed effects are included, indicating that our concerns regarding endogeneity problems affecting the OLS estimates

\footnotetext{
${ }^{16}$ Recall that we use a broad measure of consumption that includes expenditure on durables. Estimates of MPC that are larger than unity for average households in the economy still appear unrealistic both intuitively and in comparison to previous studies. For example, Parker et al. (2013) estimate that the MPC for a broad consumption measure is between 0.5 and 0.9 in response to tax rebates.
} 
may be valid. According to these estimates, the most indebted group of households with fully adjustable-interest rates reduce consumption growth by about 4 percentage points in response to a one percentage point increase in the household interest rate. The corresponding magnitude for the least indebted households is a 1 percentage point drop in consumption growth. All the coefficients are precisely estimated and significant at the $1 \%$ level. Although somewhat large (still implying an MPC a bit above unity for all household groups), the magnitudes of the point estimates are not far away from what theory predicts if all households behave as hand-to-mouth consumers.

The reduced form constitutes our main empirical specification. It provides us with an empirical test of the cash-flow channel of monetary policy operating through an effect on interest expenses that heterogeneously affects household spending. Under the assumption that monetary policy only differentially affects household consumption growth through this channel - i.e. that the exclusion restriction holds - we can use $\Delta \widetilde{r}_{i, t}$ as an instrumental variable for $\Delta r_{i, t}^{d}$. As documented in Figure 10, for households with adjustable rates there is a strong first stage of the repo rate on the household interest rate. The results are reported in Table 7 . The IV estimates are qualitatively similar to the reduced form estimates, showing similar relative responses across homeowners with different debt-to-income ratios. The magnitude of the responses are slightly larger than according to the reduced form. A one percentage point increase in the household interest rate leads to a drop in consumption growth by 5 percentage point for the most indebted households with fully adjustable-interest rates.

We emphasize that the instrumental variable estimates can only be interpreted as the causal effect if the exclusion restriction holds. What might invalidate the exclusion restriction? First, recall that all regressions include year fixed effects to account for a direct effect of the yearly changes in macroeconomic conditions, including the repo rate, on consumption growth. But the exclusion restriction will be violated if monetary policy has a heterogeneous effect on household consumption through other channels than through interest expenses. One candidate channel is that household income is somehow differentially affected by monetary policy. To investigate this problem we estimate our regressions including changes in income. As discussed in Section 3, since changes in income may have a direct effect on consumption, including changes in income in the regression equation can eliminate or mitigate problems that arise because of correlation between changes in monetary policy and the household-specific error term. The reason for including income changes is thus not that it is motivated by equation (6). Note also that because of correlations between $\Delta y_{i, t}$ and the error term, the estimated coefficient on $\Delta y_{i, t}$ cannot be interpreted based on (6). Table 8 reports reduced form and IV estimates where changes in disposable income are included as an additional regressor. ${ }^{17}$ As one would expect, income changes are highly significant and add substantially to the explanatory power in the regressions. However, the estimates of the effect of interest-rate changes are very robust to the inclusion of income changes in both specifications, as the point estimates are almost identical to what they were before. We interpret this as a clear

\footnotetext{
${ }^{17}$ Disposable income is defined as total income net of capital income and expenses.
} 
indication that our estimates are not biased because of a correlation between monetary policy and the error term.

Reduced form and IV estimation results using monetary policy shocks To further address potential concerns that changes in the repo rate are correlated with the household-specific error terms we provide reduced form and IV estimates using sensitivity-scaled monetary policy shocks. The construction of monetary policy shocks is described in Section 3. As documented in Figure 12, the magnitude of the monetary policy shocks is considerably smaller than the repo rate changes, but these innovations have a similar development as the repo rate. As a result, there is a strong first stage of monetary policy shocks on household interest rates.

For completeness, we provide results from both the reduced form and instrumental variable estimations using the monetary policy shocks. The reduced form estimates are reported in Table 9. As expected from the relation between the repo rate and the monetary policy shocks, the coefficient estimates are larger in magnitude than the repo rate reduced form estimates. Importantly, however, the qualitative results remain similar to before. The same is true when monetary policy shocks are included as an instrument for changes in household interest rates, as reported in Table 10. The estimates are slightly lower in magnitude compared earlier IV results, but highly significant and present a response that is monotonically increasing in indebtedness.

Estimation results with the explanatory variable linear in DTI According to equation (6), the impact of interest-rate changes on household consumption should vary with the household's DTI ratio. So far, we have allowed for the impact of the DTI ratio by separating homeowners into three groups depending on how indebted they are. An alternative specification, more directly in line with equation (6), is

$$
\Delta \log c_{i, t}=\beta_{0}+\beta_{1}\left(D T I_{i, t-1} \times \Delta r_{i, t}^{d}\right)+\beta_{2} D T I_{i, t-1}+\beta_{3} \mathbf{X}_{i, t}+\beta_{4} \delta_{t}+\varepsilon_{i, t}
$$

where the main explanatory variable is the linear interaction of interest rate changes with the DTI ratio.

The first two columns in Table 11 report results based on equation (6) for the full sample of households and homeowners, respectively. In the sample of homeowners our estimate of $\beta_{1}$ is approximately equal to -0.6 and is highly statistically significant. The estimate for the total sample is similar but slightly larger. According to equation (6), $\beta_{1}$ can be interpreted as the negative of the MPC. We should therefore estimate $\beta_{1}=\alpha \approx-1$ percent if all households are hand-to-mouth consumers, and a smaller impact otherwise. In this light, the estimated magnitude of the response is strong given that it is unlikely that a majority of households behave as if they are hand-to-mouth consumers. But our estimate of an MPC around 70 percent is well in line with the results in Parker et al. (2013) who estimated an MPC between 50 and 90 percent in a different setting.

Our hypothesis is that some household types are more likely to behave as hand-to-mouth consumers, i.e. as in equation (6), whereas other household types are more likely to behave as in 
equation (4). We now try to classify households according to how likely they are to be of the former type. We do that by summing the following indicator variables for each household-year combination: (i) the household is a homeowner in the high DTI group, (ii) the household is a homeowner with net DTI in the highest net DTI group, (iii) the household is a homeowner in the highest loan-to-value group, (iv) the household has disposable income per household member in the lowest quartile, (v) the household belongs to the lowest education group, and (vi) the household head is 25 years or younger. ${ }^{18}$

The final two columns in Table 11 report estimation results where we have split the sample based on how households score on these hand-to-mouth (HtM) indicators. For households in column three the sum across these six indicators is 2 or less and they are therefore relatively unlikely to behave as HtM consumers. Households in column four, on the other hand, have a sum over all indicators of 3 or more and are therefore relatively more likely to be borrowing constrained and to display HtM behavior. In line with our hypothesis, the estimated effect of interest-rate changes is largest for the households that have a high score on those indicators. The point estimate for households in column four is almost twice that for households in column three.

\section{Sensitivity Analysis and Discussion}

In this section we perform several checks to assess the robustness of our findings and to investigate the sensitivity of our results to alternative specifications.

An important part of our empirical strategy aims at identifying groups that are sensitive to interest rate changes. This implies that our main results - in particular those for high DTI households - should not be specific to this particular sample split but be robust to alternative divisions of the sample that also identify groups of households that should be differentially sensitive to interest rate changes. As an alternative to our main specification with three DTI groups, we consider sample splits based on the LTV ratio and the net debt-to-income (net DTI) ratio, which is the difference between the DTI ratio and liquid assets relative to disposable income. Both of these ratios provide alternative measures of relative indebtedness and the likelihood of households being hand-to-mouth consumers. As before, households with positive debt are separated in three groups based on the respective distribution. Reduced form estimates of the intensity-scaled repo rate for these different groups are reported in Table 12. In all cases, the change in the interest rate is estimated to have a negative impact on household consumption, and we again see that the most indebted households respond most strongly. It is not straightforward to interpret these parameter estimates based on the theoretical specification in equation (6), but we find that overall the estimates of $\beta_{1}$ are quantitatively similar to those reported in Table 7 for the same regression specification across different groups. These similarities are not surprising since according to

\footnotetext{
${ }^{18}$ Net DTI is calculated as DTI minus liquid financial assets relative to disposable income. The net DTI and LTV groups are defined similarly as the DTI groups. For DTI, net DTI, LTV, and disposable income, the classification is based on the respective variable in year $t-1$.
} 
our hypothesis sorting along these different dimensions will, to a large extent, identify the same households as being those most exposed to interest-rate changes.

To assess further how sensitive our results are to our sample and the choice of groups, we exclude households that are unlikely to be sensitive to interest rate changes. Our results, at least those for groups with medium and high DTI ratios, should be relatively insensitive to this exclusion. For this purpose we estimate two versions of our reduced form specification. First, we exclude retirees, i.e. households where the household head is 66 years or older. Second, we exclude households who hold positive liquid assets, i.e. we only include households with debt exceeding their stock of liquid assets. The results are reported in Table 13. We find similar results as before. In particular, the estimates for the high DTI group line up with what we reported in Table 6 . This indicates that few households with high DTI are old or have positive net liquid assets. In practice, the exclusion according to these criteria is therefore mainly affecting the groups of renters and households with low DTI.

For households that borrow against their houses, an increase in house prices might drive up the value of their assets and by that relax borrowing constraints. This might be particularly important for households that are highly indebted and we classify as being those most sensitive to higher interest rate expenses. We address this possibility in Table 14, where we control for growth in real estate values. As this table documents, house prices turn out to have little impact on consumption growth in our data. In addition we add controls for lagged consumption and income growth. These variables are highly significant and contribute substantially to the explanatory power in the regressions, but they have little impact on the estimates of the parameter of interest.

Although the structure of our dataset is a panel of households over seven years, the estimated response of consumption to changes in interest rates is identified from cross-sectional variation in our data. In order to highlight this we have estimated cross-sectional regressions for each year. Table 15 reports results from the reduced form specification and OLS regression of household interest rates on consumption growth. Each cell in the table reports $\beta_{1}$ for the given group in the given year. These results line up with our main results. In all years, except 2002 (and to some extent 2005), the estimate is strongly negative and statistically significant for all groups and the response is monotonically increasing in magnitude moving from low to high DTI ratio. The fact that the regressions fail for 2002 is not surprising. The average repo rate was 4.07 percent in 2002 compared to 3.98 percent in 2001 . This change in the repo rate is too small to identify changes in household interest rates. Indeed, the correlation between $\Delta \widetilde{r}_{i, t}$ and $\Delta r_{i, t}^{d}$ is negative $(-0.03$ for homeowners) in 2002 while it is positive (between 0.15 and 0.31 ) in the other years. This is also clear from comparing the reduced form estimates to the OLS estimates in the right panel of the table. The OLS estimates are relatively robust in magnitude across the sample period, including the year 2002, and similar to the estimate from the corresponding regressions in Table 5.

Finally, we explore how our results hold up in specifications that do not allow for group-year fixed effects. We do so by pooling the renters and the three groups of homeowners with debt (i.e., groups Low, Medium and High). A dummy variable which indicates the group of the household is interacted with the interest rate measure in these specifications. By restricting our specification 
to common year fixed effects we force aggregate shocks (aside from the interest rate) to have a common effect on all households which is closer to the theory of complete markets. However, the specification may be too restrictive since it also implies that any changes in reporting standards (such as bank accounts in 2006) or measurement error in a given wave of our data are not allowed to have group-specific effects on the measurement of consumption growth. One advantage of the pooled specification is that it permits a direct comparison of magnitudes across the four groups, at the expense of more restrictive assumptions.

Table 16 reports OLS estimates of individual interest rates and is thus comparable to table 5. The four specifications in the table vary by allowing or not allowing for group-specific effects of household covariates and by allowing for household fixed effects. Overall, the results are consistent with those previously reported, in particular the magnitudes of the effect. One small deviation is the relative difference between the groups High and Medium if household fixed effect are included (column 2 and 4). The effect on the group with most debt is reduced so that the magnitude of the interest rate effect becomes greater for the medium group. One reason for this reduction may be that the high group is positively selected, in the sense that it has an unobserved capacity to buffer against interest rate variability. The order of magnitude compared to renters and the least indebted homeowners is, however, preserved.

Table 17 includes changes in the repo rate rather than changes in individual rates. Columns 1-4 report specification of the reduced form, and are thus equivalent to Table 6. Overall, the reduced form estimates still imply a wedge in effects between renters and homeowners. Among homeowners, the estimates across groups are compressed relative to the results in table 6 . In particular, the effects for the medium and high groups are reduced and in line with those for the low group. Allowing for household fixed effects further reduces the effect on the most indebted group, just as in Table 16. The instrumental variable estimates in columns 5-8 (equivalent to Table 7) display a similar tendency - estimates for the highest group tend to be equal or slightly smaller than estimates for the medium group. Table 18 repeats the analysis for monetary policy shocks. The same tendency of compression of the highest group towards the medium group can be seen with this specification. In sum, the pooled regressions show that our interpretation of variable interest rates affecting the most indebted households more than the least indebted ones is not fully robust to the more restrictive specification.

\section{Conclusion}

This paper studies a transmission mechanism of monetary policy that operates through interest rate changes on households' outstanding debt. The effects on households' spending are heterogenous and depend on whether the household has debt with variable interest rates. We study this channel for monetary policy using a detailed administrative panel dataset for a large representative sample of Swedish households. The dataset contains both detailed information about the balance sheet of households and their consumption. Most Swedish households hold some share of their overall debt in loans with variable interest rates. Importantly, adjustable rate mortgage 
contracts is a standard, non-exotic, form of mortgage contract in Sweden.

We estimate a negative response of consumption growth to changes in interest expenses for all households. Highly indebted households (i.e, homeowners with a high debt-to-income ratio) who have fully adjustable-interest loans reduce consumption growth by 4 to 5 percentage points in response to a one percentage point increase in the repo rate. The response for the group of households that are least indebted is only about half in magnitude. The overall magnitude of this effect is large. However the reported estimates are an upper bound on the economy-wide magnitudes as only a fraction of households holds all of its debt in fully adjustable-interest loans. Our results are robust to a range of different specifications, including the use of monetary policy shocks as an instrumental variable for interest rates and accounting for other channels through which monetary policy might affect household consumption directly.

Our results have important implications for the role of monetary policy. They indicate that in economic environments where households are highly indebted, face restricted access to credit, and hold loans with interest rates that respond directly to variations in short interest rates, monetary policy is very potent. Monetary policy will have a stronger effect on real economic activity than in other environments since households will respond to monetary policy-induced interest rate changes by a larger magnitude than predicted by conventional estimates of the intertemporal elasticity of substitution.

It is in order to emphasize the limitations of our study and the interpretability of our results. Our focus is only on the cash-flow effect of changes in interest rates, but not on the effect that monetary policy may have on the supply of credit. This may be an important channel, particularly at times when central banks make large changes to its policy rates. We are also unable to characterize the general equilibrium effect of the cash-flow channel on aggregate consumption in the economy. Another channel that we have abstracted from but believe to be important is that monetary policy may have heterogeneous effects on household consumption by affecting the distribution of wealth in the economy. As a result of these alternative channels we are unable to make claims about the welfare implications of the cash-flow channel of monetary policy. Studying such implications remains as interesting but challenging tasks for future research. 


\section{References}

Agarwal, Sumit, \& Qian, Wenlan. 2014. Consumption and Debt Response to Unanticipated Income Shocks: Evidence from a Natural Experiment in Singapore. American Economic Review, 104(12), 4205-4230.

Agarwal, Sumit, Liu, Chunlin, \& Souleles, Nicholas. S. 2007. The Reaction of Consumer Spending and Debt to Tax Rebates - Evidence from Conumer Credit Data. Journal of Political Economy, 115(6), 986-1019.

Andersen, Asger Lau, Duus, Charlotte, \& Jensen, Thais Lærkholm. 2015 (June). Household debt and spending during the financial crisis: Evidence from Danish micro data.

Ando, Alberto, \& Modigliani, Franco. 1963. The Life Cycle Hypothesis of Saving: Aggregate Implications and Tests. American Economic Review, 53(1), 55-84.

Auclert, Adrian. 2015. Monetary Policy and the Redistribution Channel. Mimeo. MIT.

Badarinza, Cristian, Campbell, John Y., \& Ramadorai, Tarun. 2015 (September). What Calls to ARMs? International Evidence on Interest Rates and the Choice of Adjustable-Rate Mortgages. mimeo.

Baker, Scott R. 2014. Debt and the Consumption Response to Household Income Shocks. Mimeo. Kellog School of Management.

Berben, R P, Locarno, A, Morgan, J, \& Valles, J. 2004. Cross-Country Differences in Monetary Policy Transmission. Working Paper 400. European Central Bank.

Bernanke, Ben, \& Gertler, Mark. 1989. Agency Costs, Net Worth, and Business Fluctuations. American Economic Review, 79(1), 14-31.

Bernanke, Ben, \& Gertler, Mark. 1995. Inside the Black Box: The Credit Channel of Monetary Policy Transmission. Journal of Economic Perspectives, 9(4), 27-48.

Bernanke, Ben S. 2015. Monetary Policy and Inequality.

Bullard, James. 2014. Income Inequality and Monetary Policy: A Framework with Answers to Three Questions.

Calza, Alessandro, Monacelli, Tommaso, \& Stracca, Livio. 2013. Housing Finance and Monetary Policy. Journal of the European Economic Association, 11(S1), 101-122.

Campbell, John Y., \& Cocco, Joao F. 2003. Household Risk Management and Optimal Mortgage Choice. Quarterly Journal of Economics, 118, 1449-1494.

Campbell, John Y., \& Cocco, Joao F. 2015. A Model of Mortgage Default. Journal of Finance, 70(4), 1495-1554.

Campbell, John Y., \& Mankiw, N. Gregory. 1990. Permanent Income, Current Income, and Consumption. Journal of Business and Economic Statistics, 8(3), 265-279.

Carroll, Christopher D., \& Kimball, Miles S. 1990. On the Concavity of the Consumption Function. Econometrica, 64(4), 981-992. 
Casiraghi, M, Gaiotti, E, Rodano, M, \& Secchi, A. 2016. A Reverse Robin Hood? The Distributional Implications of Non-Standard Monetary Policy for Italian Households. Memeo. Bank of Italy.

Cloyne, James, Ferreira, Clodomiro, \& Surico, Paolo. 2015. Monetary Policy When Households Have Debt: New Evidence On The Transmission Mechanism. Mimeo.

Cocco, Joao F. 2013. Evidence on the Benefits of Alternative Mortgage Products. Journal of Finance, 68(4), 1663-1690.

Di Maggio, Marco, Kermani, Amir, \& Ramcharan, Rodney. 2014. Monetary Policy Pass-Through: Household Consumption and Voluntary Deleveraging. Mimeo.

Edin, P.-A., \& Fredriksson, P. 2000. LINDA - Longitudinal INdividual DAta for Sweden. Working Paper No. 2000:19. Department of Economics, Uppsala University.

Garriga, Carlos, Kydland, Finn E., \& Sustek, Roman. 2015. Mortgages and Monetary Policy. Working Paper. Federal Reserve Bank of St. Louis.

Gertler, Mark, \& Karadi, Peter. 2015. Monetary Policy Surprises, Credit Costs, and Economic Activity. American Economic Journal: Macroeconomics, 7(1), 44-76.

Greenwald, Daniel L. 2016 (February). The Mortgage Credit Channel of Macroeconomic Transmission. mimeo.

Holmberg, Ulf, Janzén, Hannes, Oscarius, Louise, van Santen, Peter, \& Spector, Erik. 2015. An Analysis of the Fixation Period for Swedish Mortgages. Mimeo. Sveriges Riksbank.

Hsieh, Chang-Tai. 2003. Do Consumers React to Anticipated Income Changes? Evidence from the Alaska Permanent Fund. American Economic Review, 93(1), 397-405.

Iacoviello, Matteo. 2005. House Prices, Borrowing Constraints and Monetary Policy in the Business Cycle. American Economic Review, 95, 739-764.

Johnson, D. S., Parker, J. A., \& Souleles, N. S. 2006. Household Expenditure and the Income Tax Rebates of 2001. American Economic Review, 96, 1589-1610.

Kaplan, Greg, Violante, Gianluca, \& Weidner, Justin. 2014. The Wealthy Hand-to-Mouth. Brookings Papers on Economic Activity.

Kashyap, A. K., \& Stein, J. C. 2000. What do a Million Observations on Banks Say About the Transmission of Monetary Policy? American Economic Review, 90(3), 407-428.

Keys, Benjamin J., Piskorski, Tomasz, Seru, Amit, \& Yao, Vincent W. 2014. Mortgage Rates, Household Balance Sheets, and the Real Economy. NBER Working Paper 20561. NBER.

Koijen, Ralph, Nieuwerburgh, Stijn Van, \& Vestman, Roine. 2015. Judging the Quality of Survey Data by Comparison with "Truth" as Measured by Administrative Records: Evidence From Sweden. In: Carroll, Christopher, Crossley, Thomas, \& Sabelhaus, John (eds), Improving the Measurement of Consumer Expenditures. NBER Book Series Studies in Income and Wealth. University of Chicago Press.

Kueng, Lorenz. 2015. Explaining Consumption Excess Sensitivity with Near-Rationality: Evidence from Large Predetermined Payments. Mimeo. Northwestern University. 
Mersch, Yves. 2014. Monetary Policy and Economic Inequality.

Mian, A., Rao, K., \& Sufi, A. 2013. Household Balance Sheets, Consumption, and the Economic Slump. Quarterly Journal of Economics, 128(4), 1687-1726.

Parker, J. A., Souleles, N. S., Johnson, D. S., \& McClelland, Robert. 2013. Consumer Spending and the Economic Stimulus Payments of 2008. American Economic Review, 103, 2530-2553.

Riksbanken. 2012 (February). Monetary Policy Report.

Riksbanken. 2015 (November). Financial Stability Report 2015:2.

Rubio, Margarita. 2011. Fixed- and Variable-Rate Mortgages, Business Cycles, and Monetary Policy. Journal of Money, Credit and Banking, 43(4), 657-688.

Shapiro, Matthew D., \& Slemrod, Joel. 2003. Consumer Response to Tax Rebates. American Economic Review.

Shapiro, Matthew D., \& Slemrod, Joel. 2009. Did the 2008 Tax Rebates Stimulate Spending? American Economic Review Papers and Proceedings, 99, 374-379.

Stephens, Mel. 2008. The Consumption Response to Predictable Changes in Discretionary Income: Evidence from the Repayment of Vehicle Loans. The Review of Economics and Statistics, 90, 241252.

Sterk, Viincent, \& Tenreyro, Silviana. 2015. The Transmission of Monetary Policy through Redistribution and Durable Purchases. Mimeo.

Zeldes, Stephen P. 1989. Consumption and Liquidity Constraints: An Empirical Investigation. Journal of Political Economy, 97(2), 305-346. 
Table 1: Summary Statistics - All Households, Renters, and By Levels of DTI

\begin{tabular}{|c|c|c|c|c|c|c|}
\hline & $\begin{array}{l}\text { All } \\
(1)\end{array}$ & $\begin{array}{c}\text { Renters } \\
(2)\end{array}$ & $\begin{array}{c}\text { No Debt } \\
\text { (3) }\end{array}$ & $\begin{array}{c}\text { Low } \\
(4)\end{array}$ & $\begin{array}{l}\text { Medium } \\
\text { (5) }\end{array}$ & $\begin{array}{l}\text { High } \\
(6)\end{array}$ \\
\hline Consumption & $\begin{array}{c}248 \\
(209,145)\end{array}$ & $\begin{array}{c}184 \\
(155,97.5)\end{array}$ & $\begin{array}{c}171 \\
(142,98.2)\end{array}$ & $\begin{array}{c}286 \\
(264,144)\end{array}$ & $\begin{array}{c}331 \\
(321,146)\end{array}$ & $\begin{array}{c}337 \\
(322,163)\end{array}$ \\
\hline Consumption growth & $\begin{array}{c}3.0 \% \\
(2.8 \%, 0.27)\end{array}$ & $\begin{array}{c}2.8 \% \\
(2.5 \%, 0.23)\end{array}$ & $\begin{array}{c}1.5 \% \\
(1.8 \%, 0.28)\end{array}$ & $\begin{array}{c}3.9 \% \\
(3.8 \%, 0.27)\end{array}$ & $\begin{array}{c}4.0 \% \\
(4.5 \%, 0.28)\end{array}$ & $\begin{array}{c}2.9 \% \\
(3.7 \%, 0.31)\end{array}$ \\
\hline Consumption equivalent & $\begin{array}{c}145 \\
(131,60.0)\end{array}$ & $\begin{array}{c}133 \\
(121,52.8)\end{array}$ & $\begin{array}{c}137 \\
(121,63.2)\end{array}$ & $\begin{array}{c}161 \\
(149,63.6)\end{array}$ & $\begin{array}{c}154 \\
(143,59.7)\end{array}$ & $\begin{array}{c}153 \\
(140,64.8)\end{array}$ \\
\hline Disposable income per capita & $\begin{array}{c}168 \\
(162,62.6)\end{array}$ & $\begin{array}{c}148 \\
(134,52.9)\end{array}$ & $\begin{array}{c}129 \\
(116,48.7)\end{array}$ & $\begin{array}{c}179 \\
(174,61.0)\end{array}$ & $\begin{array}{c}195 \\
(190,59.3)\end{array}$ & $\begin{array}{c}206 \\
(199,63.7)\end{array}$ \\
\hline Disposable income & $\begin{array}{c}256 \\
(216,144)\end{array}$ & $\begin{array}{c}182 \\
(156,91.6)\end{array}$ & $\begin{array}{c}168 \\
(140,87.1)\end{array}$ & $\begin{array}{c}300 \\
(283,141)\end{array}$ & $\begin{array}{c}353 \\
(357,138)\end{array}$ & $\begin{array}{c}359 \\
(363,147)\end{array}$ \\
\hline Disposable income growth & $\begin{array}{c}3.7 \% \\
(3.1 \%, 0.11)\end{array}$ & $\begin{array}{c}3.3 \% \\
(2.6 \%, 0.12)\end{array}$ & $\begin{array}{c}2.4 \% \\
(2.2 \%, 0.10)\end{array}$ & $\begin{array}{c}3.0 \% \\
(3.1 \%, 0.11)\end{array}$ & $\begin{array}{c}4.2 \% \\
(4.0 \%, 0.10)\end{array}$ & $\begin{array}{c}5.6 \% \\
(4,8 \%, 0.11)\end{array}$ \\
\hline Illiquid assets & $\begin{array}{c}646 \\
(320,884)\end{array}$ & $\begin{array}{c}0 \\
(0,0)\end{array}$ & $\begin{array}{c}705 \\
(501,708)\end{array}$ & $\begin{array}{c}840 \\
(618,783)\end{array}$ & $\begin{array}{c}1,098 \\
(881,803)\end{array}$ & $\begin{array}{c}1,591 \\
(1,351,1,026)\end{array}$ \\
\hline Liquid assets & $\begin{array}{c}131 \\
(36,252)\end{array}$ & $\begin{array}{c}71 \\
(2.5,191)\end{array}$ & $\begin{array}{c}331 \\
(184,426)\end{array}$ & $\begin{array}{c}189 \\
(82,289)\end{array}$ & $\begin{array}{c}126 \\
(60,189)\end{array}$ & $\begin{array}{c}95 \\
(44,150)\end{array}$ \\
\hline Debt & $\begin{array}{c}298 \\
(110,429)\end{array}$ & $\begin{array}{c}69 \\
(8.5,144)\end{array}$ & $\begin{array}{c}0.54 \\
(0,7.18)\end{array}$ & $\begin{array}{c}163 \\
(130,139)\end{array}$ & $\begin{array}{c}507 \\
(490,229)\end{array}$ & $\begin{array}{c}995 \\
(903,526)\end{array}$ \\
\hline Debt-to-Income & $\begin{array}{c}0.92 \\
(0.49,1.18)\end{array}$ & $\begin{array}{c}0.36 \\
(0.05,0.82)\end{array}$ & $\begin{array}{c}0.00 \\
(0,0.04)\end{array}$ & $\begin{array}{c}0.53 \\
(0.52,0.35)\end{array}$ & $\begin{array}{c}1.45 \\
(1.42,0.36)\end{array}$ & $\begin{array}{c}2.82 \\
(2.56,1.11)\end{array}$ \\
\hline Loan-to-Value & $\begin{array}{c}0.64 \\
(0.40,43)\end{array}$ & $\begin{array}{c}\mathrm{n} / \mathrm{a} \\
(\mathrm{n} / \mathrm{a})\end{array}$ & $\begin{array}{c}0.00 \\
(0,0.04)\end{array}$ & $\begin{array}{c}0.86 \\
(0.21,83.0)\end{array}$ & $\begin{array}{c}0.70 \\
(0.54,1.66)\end{array}$ & $\begin{array}{c}0.80 \\
(0.69,1.48)\end{array}$ \\
\hline Liquid Assets-to-Income & $\begin{array}{c}0.59 \\
(0.14,1.30)\end{array}$ & $\begin{array}{c}0.45 \\
(0.01,1.23)\end{array}$ & $\begin{array}{c}1.96 \\
(1.19,2.44)\end{array}$ & $\begin{array}{c}0.60 \\
(0.29,0.90)\end{array}$ & $\begin{array}{c}0.36 \\
(0.18,0.55)\end{array}$ & $\begin{array}{c}0.27 \\
(0.13,0.44)\end{array}$ \\
\hline Interest rate & $\begin{array}{c}5.5 \% \\
(5.0 \%, 0.04)\end{array}$ & $\begin{array}{c}5.8 \% \\
(4.7 \%, 0.06)\end{array}$ & $\begin{array}{c}4.2 \% \\
(2.3 \%, 0.05)\end{array}$ & $\begin{array}{c}5.9 \% \\
(5.5 \%, 0.03)\end{array}$ & $\begin{array}{c}5.2 \% \\
(5.2 \%, 0.02)\end{array}$ & $\begin{array}{c}4.76 \% \\
(5.7 \%, 0.01)\end{array}$ \\
\hline Interest share & $\begin{array}{c}4.3 \% \\
(2.0 \%, 0.06)\end{array}$ & $\begin{array}{c}1.28 \% \\
(0.00,0.03)\end{array}$ & $\begin{array}{c}0.02 \% \\
(0.00,0.00)\end{array}$ & $\begin{array}{c}2.82 \% \\
(2.6 \%, 0.02)\end{array}$ & $\begin{array}{c}7.5 \% \\
(7.2 \%, 0.03)\end{array}$ & $\begin{array}{c}13.1 \% \\
(12.3 \%, 0.05)\end{array}$ \\
\hline Correlation measure & $\begin{array}{c}0.38 \\
(0.55,0.52)\end{array}$ & $\begin{array}{c}0.13 \\
(0.21,0.57)\end{array}$ & $\begin{array}{c}0.21 \\
(0.53,0.79)\end{array}$ & $\begin{array}{c}0.42 \\
(0.57,0.50)\end{array}$ & $\begin{array}{c}0.53 \\
(0.66,0.42)\end{array}$ & $\begin{array}{c}0.53 \\
(0.67,0.43)\end{array}$ \\
\hline Age & $\begin{array}{c}55 \\
(52,17)\end{array}$ & $\begin{array}{c}56 \\
(53,19)\end{array}$ & $\begin{array}{c}71 \\
(74,14)\end{array}$ & $\begin{array}{c}55 \\
(55,13)\end{array}$ & $\begin{array}{c}49 \\
(47,12)\end{array}$ & $\begin{array}{c}46 \\
(43,11)\end{array}$ \\
\hline Education & $\begin{array}{c}2.09 \\
(2.00,0.62)\end{array}$ & $\begin{array}{c}1.98 \\
(2.00,0.61)\end{array}$ & $\begin{array}{c}1.90 \\
2.00,0.52)\end{array}$ & $\begin{array}{c}2.10 \\
(2.00,0,63)\end{array}$ & $\begin{array}{c}2.21 \\
(2.00,0.59)\end{array}$ & $\begin{array}{c}2.35 \\
(2.00,0.59)\end{array}$ \\
\hline Household size & $\begin{array}{c}2.30 \\
(2.00,1.50)\end{array}$ & $\begin{array}{c}1.80 \\
(1.00,1.35)\end{array}$ & $\begin{array}{c}1.38 \\
(1.00,0.66)\end{array}$ & $\begin{array}{c}2.39 \\
(2.00,1.36)\end{array}$ & $\begin{array}{c}3.13 \\
(3.00,1.48)\end{array}$ & $\begin{array}{c}3.25 \\
(4.00,1.47)\end{array}$ \\
\hline Observations & 304,694 & 124,313 & 32,639 & 49,247 & 49,248 & 49,247 \\
\hline
\end{tabular}

Notes: No Debt, Low, Medium and High represent groups separated based on homeowners' Debt-to-Income (DTI). The three last groups have positive debt in the previous year and the sample is split in thirds based on the previous year's DTI distribution. Values in parenthesis are (median, s.d.). Values are in 1,000 Swedish Krona or in percentage changes. Consumption equivalent is a scaled measure of consumption that accounts for the composition of the household. The scaling factor is generated by assigning a value of 1 to the first household member, of 0.7 to each additional adult and of 0.5 to each child. 
Table 2: Summary Statistics and Balance by Interest Rate Variability

\begin{tabular}{|c|c|c|c|}
\hline & $\begin{array}{l}\text { Low } \\
(1)\end{array}$ & $\begin{array}{l}\text { High } \\
(2)\end{array}$ & $\begin{array}{c}\text { High vs. Low } \\
\text { (3) }\end{array}$ \\
\hline Consumption & $\begin{array}{c}310 \\
(295,149)\end{array}$ & $\begin{array}{c}324 \\
(310,156)\end{array}$ & $\begin{array}{c}14^{* * *} \\
(1.455)\end{array}$ \\
\hline Consumption growth & $\begin{array}{c}3.3 \% \\
(3.3 \%, 0.29)\end{array}$ & $\begin{array}{c}3.9 \% \\
(4.4 \%, 0.29)\end{array}$ & $\begin{array}{c}0.005^{* * *} \\
(0.001)\end{array}$ \\
\hline Disposable income & $\begin{array}{c}329 \\
(331,143)\end{array}$ & $\begin{array}{c}342 \\
(344,146)\end{array}$ & $\begin{array}{l}13^{* * *} \\
(0.000)\end{array}$ \\
\hline Disposable income growth & $\begin{array}{c}4.2 \% \\
(3.9 \%, 0.11)\end{array}$ & $\begin{array}{c}4.2 \% \\
(3.9 \%, 0.11)\end{array}$ & $\begin{array}{c}-0.000 \\
(10.375)\end{array}$ \\
\hline Illiquid assets & $\begin{array}{c}1,120 \\
(884,908)\end{array}$ & $\begin{array}{c}1,225 \\
(968,950)\end{array}$ & $\begin{array}{l}105^{* * *} \\
(9.540)\end{array}$ \\
\hline Liquid assets & $\begin{array}{c}136 \\
(57,219)\end{array}$ & $\begin{array}{c}141 \\
(61,229)\end{array}$ & $\begin{array}{c}5.4^{* *} \\
(2.236)\end{array}$ \\
\hline Liquid Assets-to-Income & $\begin{array}{c}0.41 \\
(0.18,0.68)\end{array}$ & $\begin{array}{c}0.42 \\
(0.18,0.70)\end{array}$ & $\begin{array}{c}0.010 \\
(0.007)\end{array}$ \\
\hline Debt & $\begin{array}{c}514 \\
(405,480)\end{array}$ & $\begin{array}{c}583 \\
(482,484)\end{array}$ & $\begin{array}{c}69^{* * *} \\
(5.033)\end{array}$ \\
\hline Debt-to-Income & $\begin{array}{c}1.50 \\
(1.32,1.21)\end{array}$ & $\begin{array}{c}1.66 \\
(1.49,1.14)\end{array}$ & $\begin{array}{c}0.155^{* * *} \\
(0.012)\end{array}$ \\
\hline Loan-to-Value & $\begin{array}{c}0.90 \\
(0.48,66.7)\end{array}$ & $\begin{array}{c}0.65 \\
(0.52,2.00)\end{array}$ & $\begin{array}{l}-0.249 \\
(0.243)\end{array}$ \\
\hline Interest rate & $\begin{array}{c}5.5 \% \\
(5.3 \%, 0.03)\end{array}$ & $\begin{array}{c}5.0 \% \\
(4.8 \%, 0.02)\end{array}$ & $\begin{array}{c}-0.508^{* * *} \\
(0.021)\end{array}$ \\
\hline Correlation measure & $\begin{array}{c}0.156 \\
(0.292,0.430)\end{array}$ & $\begin{array}{c}0.833 \\
(0.836,0.100)\end{array}$ & $\begin{array}{c}0.677^{* * *} \\
(0.003)\end{array}$ \\
\hline Age & $\begin{array}{c}50 \\
(47,13)\end{array}$ & $\begin{array}{c}50 \\
(47,13)\end{array}$ & $\begin{array}{c}0.058 \\
(0.140)\end{array}$ \\
\hline Education & $\begin{array}{c}2.20 \\
(2.00,0.62)\end{array}$ & $\begin{array}{c}2.23 \\
(2.00,0.61)\end{array}$ & $\begin{array}{c}0.032^{* * *} \\
(0.007)\end{array}$ \\
\hline Household size & $\begin{array}{c}2.86 \\
(3.00,1.48)\end{array}$ & $\begin{array}{c}2.96 \\
(3.00,1.49)\end{array}$ & $\begin{array}{c}0.101^{* * *} \\
(0.016)\end{array}$ \\
\hline Observations & 76,031 & 73,656 & 149,687 \\
\hline
\end{tabular}

Notes: Columns (1) and (2) report summary statistics by groups with different degrees of interest rate variability, where Low and High represent groups with a correlation of household interest rates with the repo rate below or above the median correlation across homeowners. Values are in 1,000 Swedish Krona or in percentage changes. Values in parenthesis are (median, s.d.). Column (3) reports regression coefficients from single variable regressions on an indicator of having a highly variable interest rate. Standard errors, reported in parenthesis below, are clustered at the household level. 
Table 3: Effects of repo rate changes on interest payments

\begin{tabular}{lccccc}
\hline & Renters & Low & Medium & High & All, Excl. No Debt \\
& $(1)$ & $(2)$ & $(3)$ & $(4)$ & $(5)$ \\
\hline$\Delta$ repo $t^{*}$ & $40.992^{* * *}$ & $63.755^{* * *}$ & $158.417^{* * *}$ & $350.740^{* * *}$ & $146.511^{* * *}$ \\
Constant & $(1.751)$ & $(1.744)$ & $(3.029)$ & $(5.284)$ & $(1.608)$ \\
& $0.521^{* * *}$ & $-0.290^{* * *}$ & $-0.581^{* * *}$ & $-0.431^{* * *}$ & $-0.118^{* * *}$ \\
& $(0.014)$ & $(0.014)$ & $(0.024)$ & $(0.042)$ & $(0.013)$ \\
Observations & & & & & \\
$R^{2}$ & 65,141 & 47,000 & 49,237 & 49,246 & 210,624 \\
\hline
\end{tabular}

Notes: The sample is restricted to households for which $\Delta r_{i, t}^{d}$ is non-missing. ${ }^{*}{ }^{* *}$ and ${ }^{* * *}$ denotes significance at the 10 percent, 5 percent and 1 percent level, respectively.

Table 4: Effects of household interest rate changes on interest payments

\begin{tabular}{lccccc}
\hline & Renters & Low & Medium & High & All, Excl. No Debt \\
& $(1)$ & $(2)$ & $(3)$ & $(4)$ & $(5)$ \\
\hline$\Delta r_{i, t}^{d}$ & $29.544^{* * *}$ & $31.891^{* * *}$ & $358.417^{* * *}$ & $852.345^{* * *}$ & $67.071^{* * *}$ \\
& $(0.328)$ & $(0.503)$ & $(1.619)$ & $(2.852)$ & $(0.467)$ \\
Constant & $0.413^{* * *}$ & $-0.300^{* * *}$ & $0.148^{* * *}$ & $1.160^{* * *}$ & $-0.226^{* * *}$ \\
& $(0.013)$ & $(0.013)$ & $(0.018)$ & $(0.027)$ & $(0.012)$ \\
& & & & & \\
Observations & 65,141 & 47,000 & 49,237 & 49,246 & 210,624 \\
R-squared & 0.111 & 0.079 & 0.499 & 0.645 & 0.089 \\
\hline
\end{tabular}

Notes: ${ }^{*}{ }^{* *}$ and ${ }^{* * *}$ denotes significance at the 10 percent, 5 percent and 1 percent level, respectively.

Table 5: OLS Estimates of Changes in Household Interest Rates, $\Delta r_{i, t}^{d}$, on Consumption Growth

\begin{tabular}{|c|c|c|c|c|c|c|c|c|}
\hline & \multicolumn{2}{|c|}{ Renters } & \multicolumn{2}{|c|}{ Low } & \multicolumn{2}{|c|}{ Medium } & \multicolumn{2}{|c|}{ High } \\
\hline & $(1)$ & $(2)$ & (3) & $(4)$ & (5) & (6) & $(7)$ & $(8)$ \\
\hline$\Delta r_{i, t}^{d}$ & $\begin{array}{c}-1.326^{* * *} \\
(0.028)\end{array}$ & $\begin{array}{c}-1.358^{* * *} \\
(0.034)\end{array}$ & $\begin{array}{c}-2.365^{* * *} \\
(0.066)\end{array}$ & $\begin{array}{c}-1.925^{* * *} \\
(0.072)\end{array}$ & $\begin{array}{c}-7.949^{* * *} \\
(0.219)\end{array}$ & $\begin{array}{c}-6.686^{* * *} \\
(0.233)\end{array}$ & $\begin{array}{c}-7.856^{* * *} \\
(0.365)\end{array}$ & $\begin{array}{c}-6.828^{* * *} \\
(0.408)\end{array}$ \\
\hline$D T I_{i, t-1}$ & $\begin{array}{c}-0.006^{* * * *} \\
(0.001)\end{array}$ & $\begin{array}{c}-0.101^{* * *} \\
(0.015)\end{array}$ & $\begin{array}{c}-0.021^{* * *} \\
(0.004)\end{array}$ & $\begin{array}{c}-0.484^{* * *} \\
(0.014)\end{array}$ & $\begin{array}{c}-0.022^{* * *} \\
(0.004)\end{array}$ & $\begin{array}{c}-0.392^{* * *} \\
(0.011)\end{array}$ & $\begin{array}{l}-0.001 \\
(0.001)\end{array}$ & $\begin{array}{c}-0.087^{* * *} \\
(0.007)\end{array}$ \\
\hline Year fixed effects & Yes & Yes & Yes & Yes & Yes & Yes & Yes & Yes \\
\hline Household fixed effects & No & Yes & No & Yes & No & Yes & No & Yes \\
\hline Observations & 65,141 & 65,141 & 47,000 & 47,000 & 49,237 & 49,237 & 49,246 & 49,246 \\
\hline$R^{2}$ & 0.062 & 0.074 & 0.067 & 0.101 & 0.092 & 0.118 & 0.054 & 0.058 \\
\hline
\end{tabular}

Notes: All specifications include a fourth polynomial in age, household size, and growth in household size. Standard errors in parenthesis are clustered at the household level. * ${ }^{* *}$ and ${ }^{* * *}$ denotes significance at the 10 percent, 5 percent and 1 percent level, respectively. 
Table 6: Reduced Form Estimates of $\Delta \widetilde{r}_{i, t}$ on Consumption Growth

\begin{tabular}{|c|c|c|c|c|c|c|c|c|}
\hline & \multicolumn{2}{|c|}{ Renters } & \multicolumn{2}{|c|}{ Low } & \multicolumn{2}{|c|}{ Medium } & \multicolumn{2}{|c|}{ High } \\
\hline & $(1)$ & $(2)$ & (3) & $(4)$ & (5) & $(6)$ & $(7)$ & $(8)$ \\
\hline$\Delta \widetilde{r}_{i, t}$ & $\begin{array}{c}-2.232^{* * *} \\
(0.179)\end{array}$ & $\begin{array}{c}-1.557^{* * *} \\
(0.232)\end{array}$ & $\begin{array}{c}-3.666^{* * *} \\
(0.271)\end{array}$ & $\begin{array}{c}-1.188^{* * *} \\
(0.349)\end{array}$ & $\begin{array}{c}-4.863^{* * *} \\
(0.351)\end{array}$ & $\begin{array}{c}-1.945^{* * *} \\
(0.454)\end{array}$ & $\begin{array}{c}-4.919 * * * \\
(0.359)\end{array}$ & $\begin{array}{c}-3.780^{* * *} \\
(0.454)\end{array}$ \\
\hline$D T I_{i, t-1}$ & $\begin{array}{c}-0.013^{* * *} \\
(0.002)\end{array}$ & $\begin{array}{c}-0.153^{* * *} \\
(0.022)\end{array}$ & $\begin{array}{c}-0.028^{* * *} \\
(0.004)\end{array}$ & $\begin{array}{c}-0.555^{* * *} \\
(0.014)\end{array}$ & $\begin{array}{c}-0.026^{* * * *} \\
(0.005)\end{array}$ & $\begin{array}{c}-0.481^{* * *} \\
(0.011)\end{array}$ & $\begin{array}{c}-0.003^{* * *} \\
(0.001)\end{array}$ & $\begin{array}{c}-0.102^{* * *} \\
(0.007)\end{array}$ \\
\hline Year fixed effects & Yes & Yes & Yes & Yes & Yes & Yes & Yes & Yes \\
\hline Household fixed effects & No & Yes & No & Yes & No & Yes & No & Yes \\
\hline Observations & 63,893 & 63,893 & 49,247 & 49,247 & 49,248 & 49,248 & 49,247 & 49,247 \\
\hline$R^{2}$ & 0.014 & 0.034 & 0.019 & 0.067 & 0.015 & 0.067 & 0.009 & 0.023 \\
\hline
\end{tabular}

Notes: All specifications include a fourth polynomial in age, household size, and growth in household size. Standard errors in parenthesis are clustered at the household level. * ${ }^{* *}$ and ${ }^{* * *}$ denotes significance at the 10 percent, 5 percent and 1 percent level, respectively.

Table 7: IV Estimates - Instrument: $\Delta \widetilde{r}_{i, t}$

\begin{tabular}{|c|c|c|c|c|c|c|c|c|}
\hline & \multicolumn{2}{|c|}{ Renters } & \multicolumn{2}{|c|}{ Low } & \multicolumn{2}{|c|}{ Medium } & \multicolumn{2}{|c|}{ High } \\
\hline & $(1)$ & $(2)$ & (3) & $(4)$ & (5) & (6) & (7) & $(8)$ \\
\hline$\Delta r_{i, t}^{d}$ & $\begin{array}{c}-1.041^{* * *} \\
(0.107)\end{array}$ & $\begin{array}{c}-0.902^{* * *} \\
(0.143)\end{array}$ & $\begin{array}{c}-2.606^{* * *} \\
(0.210)\end{array}$ & $\begin{array}{c}-1.306^{* * *} \\
(0.301)\end{array}$ & $\begin{array}{c}-5.350^{* * *} \\
(0.419)\end{array}$ & $\begin{array}{c}-2.389^{* * *} \\
(0.553)\end{array}$ & $\begin{array}{c}-6.581^{* * *} \\
(0.540)\end{array}$ & $\begin{array}{c}-5.160^{* * *} \\
(0.613)\end{array}$ \\
\hline$D T I_{i, t-1}$ & $\begin{array}{c}-0.009^{* *} \\
(0.001)\end{array}$ & $\begin{array}{c}-0.128^{* * *} \\
(0.021)\end{array}$ & $\begin{array}{c}-0.021^{* * *} \\
(0.004)\end{array}$ & $\begin{array}{c}-0.519^{* * * *} \\
(0.022)\end{array}$ & $\begin{array}{c}-0.023^{* * *} \\
(0.005)\end{array}$ & $\begin{array}{c}-0.451^{* * *} \\
(0.014)\end{array}$ & $\begin{array}{c}-0.002 \\
(0.001)\end{array}$ & $\begin{array}{c}-0.091^{* * *} \\
(0.007)\end{array}$ \\
\hline Year fixed effects & Yes & Yes & Yes & Yes & Yes & Yes & Yes & Yes \\
\hline Household fixed effects & No & Yes & No & Yes & No & Yes & No & Yes \\
\hline Observations & 57,002 & 57,002 & 47,000 & 47,000 & 49,237 & 49,237 & 49,246 & 49,246 \\
\hline$R^{2}$ & 0.061 & 0.076 & 0.066 & 0.098 & 0.084 & 0.096 & 0.052 & 0.056 \\
\hline
\end{tabular}

Notes: All specifications include a fourth polynomial in age, household size, and growth in household size. Standard errors in parenthesis are clustered at the household level. ${ }^{*}{ }^{* *}$ and ${ }^{* * *}$ denotes significance at the 10 percent, 5 percent and 1 percent level, respectively. 
Table 8: Reduced Form and IV Estimates Using $\Delta \widetilde{r}_{i, t}$ and Controlling for Income Growth

\begin{tabular}{|c|c|c|c|c|c|c|c|c|}
\hline & \multicolumn{4}{|c|}{ Reduced Form } & \multicolumn{4}{|c|}{ IV } \\
\hline & $\begin{array}{l}\text { Renters } \\
\text { (1) }\end{array}$ & $\begin{array}{l}\text { Low } \\
(2)\end{array}$ & $\begin{array}{l}\text { Medium } \\
\text { (3) }\end{array}$ & $\begin{array}{l}\text { High } \\
(4)\end{array}$ & $\begin{array}{l}\text { Renters } \\
\text { (5) }\end{array}$ & $\begin{array}{l}\text { Low } \\
(6)\end{array}$ & $\begin{array}{c}\text { Medium } \\
\text { (7) }\end{array}$ & $\begin{array}{l}\text { High } \\
(8)\end{array}$ \\
\hline$\Delta \widetilde{r}_{i, t}$ & $\begin{array}{c}-1.707^{* * *} \\
(0.237)\end{array}$ & $\begin{array}{c}-1.041^{* * *} \\
(0.341)\end{array}$ & $\begin{array}{c}-1.840^{* * * *} \\
(0.447)\end{array}$ & $\begin{array}{c}-3.710^{* * *} \\
(0.442)\end{array}$ & & & & \\
\hline$\Delta r_{i, t}^{d}$ & & & & & $\begin{array}{c}-1.042^{* * *} \\
(0.139)\end{array}$ & $\begin{array}{c}-1.180^{* * *} \\
(0.293)\end{array}$ & $\begin{array}{c}-2.242^{* * *} \\
(0.544)\end{array}$ & $\begin{array}{c}-5.060^{* * *} \\
(0.596)\end{array}$ \\
\hline$D T I_{i, t-1}$ & $\begin{array}{c}-0.248^{* * *} \\
(0.036)\end{array}$ & $\begin{array}{c}-0.630^{* * * *} \\
(0.014)\end{array}$ & $\begin{array}{c}-0.600^{* * * *} \\
(0.013)\end{array}$ & $\begin{array}{c}-0.157^{* * * *} \\
(0.010)\end{array}$ & $\begin{array}{c}-0.225^{* * *} \\
(0.036)\end{array}$ & $\begin{array}{c}-0.607^{* * *} \\
(0.022)\end{array}$ & $\begin{array}{c}-0.571^{* * *} \\
(0.015)\end{array}$ & $\begin{array}{c}-0.148^{* * *} \\
(0.010)\end{array}$ \\
\hline$\Delta \log y_{i, t}$ & $\begin{array}{c}0.617^{* * *} \\
(0.021)\end{array}$ & $\begin{array}{c}0.605^{* * *} \\
(0.025)\end{array}$ & $\begin{array}{c}0.814^{* * *} \\
(0.037)\end{array}$ & $\begin{array}{c}0.638^{* * *} \\
(0.026)\end{array}$ & $\begin{array}{c}0.615^{* * *} \\
(0.022)\end{array}$ & $\begin{array}{c}0.617^{* * * *} \\
(0.026)\end{array}$ & $\begin{array}{c}0.813^{* * * *} \\
(0.037)\end{array}$ & $\begin{array}{c}0.660^{* * * *} \\
(0.026)\end{array}$ \\
\hline Year fixed effects & Yes & Yes & Yes & Yes & Yes & Yes & Yes & Yes \\
\hline Household fixed effects & Yes & Yes & Yes & Yes & Yes & Yes & Yes & Yes \\
\hline Observations & 63,884 & 49,245 & 49,244 & 49,241 & 56,367 & 44,785 & 45,688 & 47,080 \\
\hline$R^{2}$ & 0.190 & 0.118 & 0.134 & 0.072 & 0.239 & 0.149 & 0.162 & 0.108 \\
\hline
\end{tabular}

Notes: All specifications include a fourth polynomial in age, household size, and growth in household size. Standard errors in parenthesis are clustered at the household level. ${ }^{*}{ }^{* *}$ and ${ }^{* * *}$ denotes significance at the 10 percent, 5 percent and 1 percent level, respectively.

Table 9: Reduced Form Estimates of $\widetilde{M P S}_{i, t}$ on Consumption Growth

\begin{tabular}{|c|c|c|c|c|c|c|c|c|}
\hline & \multicolumn{2}{|c|}{ Renters } & \multicolumn{2}{|c|}{ Low } & \multicolumn{2}{|c|}{ Medium } & \multicolumn{2}{|c|}{ High } \\
\hline & (1) & (2) & (3) & $(4)$ & (5) & (6) & (7) & (8) \\
\hline$M P S_{i, t}$ & $\begin{array}{c}-10.102^{* * *} \\
(1.063)\end{array}$ & $\begin{array}{c}-6.013^{* * * *} \\
(1.429)\end{array}$ & $\begin{array}{c}-20.034^{* * *} \\
(1.593)\end{array}$ & $\begin{array}{c}-5.811^{* * *} \\
(2.103)\end{array}$ & $\begin{array}{c}-26.185^{* * * *} \\
(2.080)\end{array}$ & $\begin{array}{c}-12.179^{* * * *} \\
(2.718)\end{array}$ & $\begin{array}{c}-23.651^{* * *} \\
(2.133)\end{array}$ & $\begin{array}{c}-16.579^{* * *} \\
(2.640)\end{array}$ \\
\hline$D T I_{i, t-1}$ & $\begin{array}{c}-0.013^{* * *} \\
(0.002)\end{array}$ & $\begin{array}{c}-0.154^{* * *} \\
(0.022)\end{array}$ & $\begin{array}{c}-0.028^{* * *} \\
(0.004)\end{array}$ & $\begin{array}{c}-0.556^{* * *} \\
(0.014)\end{array}$ & $\begin{array}{c}-0.026^{* * * *} \\
(0.005)\end{array}$ & $\begin{array}{c}-0.482^{* * *} \\
(0.011)\end{array}$ & $\begin{array}{c}-0.003^{* *} \\
(0.001)\end{array}$ & $\begin{array}{c}-0.103^{* * *} \\
(0.007)\end{array}$ \\
\hline Year fixed effects & Yes & Yes & Yes & Yes & Yes & Yes & Yes & Yes \\
\hline Household fixed effects & No & Yes & No & Yes & No & Yes & No & Yes \\
\hline Observations & 63,893 & 63,893 & 49,247 & 49,247 & 49,248 & 49,248 & 49,247 & 49,247 \\
\hline$R^{2}$ & 0.013 & 0.034 & 0.018 & 0.067 & 0.015 & 0.067 & 0.008 & 0.022 \\
\hline
\end{tabular}

Notes: All specifications include a fourth polynomial in age, household size, and growth in household size. Standard errors in parenthesis are clustered at the household level. ${ }^{*}, * *$ and ${ }^{* * *}$ denotes significance at the 10 percent, 5 percent and 1 percent level, respectively. 
Table 10: IV estimates - Instrument: $\widetilde{M P S}_{i, t}$

\begin{tabular}{|c|c|c|c|c|c|c|c|c|}
\hline & \multicolumn{2}{|c|}{ Renters } & \multicolumn{2}{|c|}{ Low } & \multicolumn{2}{|c|}{ Medium } & \multicolumn{2}{|c|}{ High } \\
\hline & (1) & (2) & (3) & (4) & (5) & (6) & (7) & (8) \\
\hline$\Delta r_{i, t}^{d}$ & $\begin{array}{c}-0.951^{* * *} \\
(0.128)\end{array}$ & $\begin{array}{c}-0.796^{* * *} \\
(0.199)\end{array}$ & $\begin{array}{c}-2.884^{* * *} \\
(0.250)\end{array}$ & $\begin{array}{c}-1.441^{* * *} \\
(0.436)\end{array}$ & $\begin{array}{c}-5.434^{* * *} \\
(0.460)\end{array}$ & $\begin{array}{c}-2.960^{* * *} \\
(0.658)\end{array}$ & $\begin{array}{c}-5.604^{* * *} \\
(0.545)\end{array}$ & $\begin{array}{c}-4.076^{* * *} \\
(0.655)\end{array}$ \\
\hline$D T I_{i, t-1}$ & $\begin{array}{c}-0.010^{* * *} \\
(0.001)\end{array}$ & $\begin{array}{c}-0.130^{* * *} \\
(0.021)\end{array}$ & $\begin{array}{c}-0.020^{* * *} \\
(0.004)\end{array}$ & $\begin{array}{c}-0.511^{* * *} \\
(0.028)\end{array}$ & $\begin{array}{c}-0.023^{* * *} \\
(0.005)\end{array}$ & $\begin{array}{c}-0.443^{* * *} \\
(0.015)\end{array}$ & $\begin{array}{l}-0.002 \\
(0.001)\end{array}$ & $\begin{array}{c}-0.094^{* * *} \\
(0.007)\end{array}$ \\
\hline Observations & 57,002 & 56,377 & 47,000 & 44,787 & 49,237 & 45,693 & 49,246 & 47,089 \\
\hline$R^{2}$ & 0.060 & 0.073 & 0.064 & 0.099 & 0.084 & 0.102 & 0.050 & 0.052 \\
\hline
\end{tabular}

Notes: All specifications include a fourth polynomial in age, household size, and growth in household size. Standard errors in parenthesis are clustered at the household level. ${ }^{*},{ }^{* *}$ and ${ }^{* * *}$ denotes significance at the 10 percent, 5 percent and 1 percent level, respectively.

Table 11: Reduced Form Estimates of $D T I \times \Delta \widetilde{r}_{i, t}$ on Consumption Growth

\begin{tabular}{lcccc}
\hline \hline & & & \multicolumn{2}{c}{ Households by indicators of HtM } \\
\cline { 3 - 5 } & All & Homeowners & sum(indicator) $\leq 2$ & sum(indicator) $\geq 3$ \\
& $(1)$ & $(2)$ & $(3)$ & $(4)$ \\
\hline$D T I \times \Delta \widetilde{r}_{i, t}$ & $-0.768^{* * *}$ & $-0.630^{* * *}$ & $-0.736^{* * *}$ & $-1.313^{* * *}$ \\
& $(0.123)$ & $(0.138)$ & $(0.170)$ & $(0.207)$ \\
$D T I_{i, t-1}$ & $-0.150^{* * *}$ & $-0.148^{* * *}$ & $-0.190^{* * *}$ & $-0.115^{* * *}$ \\
& $(0.006)$ & $(0.005)$ & $(0.011)$ & $(0.009)$ \\
Year fixed effects & & & & \\
Household fixed effects & Yes & Yes & Yes & Yes \\
Observations & 213,580 & 149,687 & Yes & Yes \\
$R^{2}$ & 0.032 & 0.032 & 0.036 & 27,176 \\
\hline
\end{tabular}

Notes: All specifications include a fourth polynomial in age, household size, and growth in household size. Standard errors in parenthesis are clustered at the household level. *,** and *** denotes significance at the 10 percent, 5 percent and 1 percent level, respectively. 
Table 12: Reduced Form Estimates Using $\Delta \widetilde{r}_{i, t}-$ By Net DTI and LTV Groups

\begin{tabular}{|c|c|c|c|c|c|c|}
\hline & \multicolumn{3}{|c|}{ Net DTI } & \multicolumn{3}{|c|}{ LTV } \\
\hline & $\begin{array}{c}\text { Low } \\
(1)\end{array}$ & $\begin{array}{l}\text { Medium } \\
\text { (2) }\end{array}$ & $\begin{array}{c}\text { High } \\
\text { (3) }\end{array}$ & $\begin{array}{c}\text { Low } \\
(4)\end{array}$ & $\begin{array}{l}\text { Medium } \\
\text { (5) }\end{array}$ & $\begin{array}{c}\text { High } \\
(6)\end{array}$ \\
\hline$\Delta \widetilde{r}_{i, t}$ & $\begin{array}{c}-2.508^{* * *} \\
(0.361)\end{array}$ & $\begin{array}{c}-2.415^{* * *} \\
(0.438)\end{array}$ & $\begin{array}{c}-4.089^{* * *} \\
(0.449)\end{array}$ & $\begin{array}{c}-2.189^{* * *} \\
(0.381)\end{array}$ & $\begin{array}{c}-1.518^{* * *} \\
(0.489)\end{array}$ & $\begin{array}{c}-4.987^{* * *} \\
(0.444)\end{array}$ \\
\hline$n_{e t} D T I_{i, t-1}$ & $\begin{array}{c}-0.189^{* * *} \\
(0.011)\end{array}$ & $\begin{array}{c}-0.588^{* * *} \\
(0.010)\end{array}$ & $\begin{array}{c}-0.135^{* * *} \\
(0.008)\end{array}$ & & & \\
\hline$L T V_{i, t-1}$ & & & & $\begin{array}{c}-1.317^{* * *} \\
(0.037)\end{array}$ & $\begin{array}{c}1.268^{* * *} \\
(0.029)\end{array}$ & $\begin{array}{c}-0.000^{* * *} \\
(0.000)\end{array}$ \\
\hline Year fixed effects & Yes & Yes & Yes & Yes & Yes & Yes \\
\hline Household fixed effects & Yes & Yes & Yes & Yes & Yes & Yes \\
\hline Observations & 49,247 & 49,248 & 49,247 & 49,247 & 49,248 & 49,247 \\
\hline$R^{2}$ & 0.062 & 0.125 & 0.035 & 0.051 & 0.071 & 0.010 \\
\hline
\end{tabular}

Notes: All specifications include a fourth polynomial in age, household size, and growth in household size. Standard errors in parenthesis are clustered at the household level. * ** and *** denotes significance at the 10 percent, 5 percent and 1 percent level, respectively.

Table 13: Reduced Form Estimates Using $\Delta \widetilde{r}_{i, t}-$ Excluding retirees and net liquid asset holders

\begin{tabular}{|c|c|c|c|c|c|c|c|c|}
\hline & \multicolumn{4}{|c|}{ Excluding retirees } & \multicolumn{4}{|c|}{ Excluding net liquid asset holders } \\
\hline & $\begin{array}{c}\text { Renters } \\
(1)\end{array}$ & $\begin{array}{c}\text { Low } \\
(2)\end{array}$ & $\begin{array}{l}\text { Medium } \\
\text { (3) }\end{array}$ & $\begin{array}{c}\text { High } \\
(4)\end{array}$ & $\begin{array}{c}\text { Renters } \\
\text { (5) }\end{array}$ & $\begin{array}{c}\text { Low } \\
(6)\end{array}$ & $\begin{array}{c}\text { Medium } \\
\text { (7) }\end{array}$ & $\begin{array}{c}\text { High } \\
(8)\end{array}$ \\
\hline$\Delta \widetilde{r}_{i, t}$ & $\begin{array}{c}-1.705^{* * *} \\
(0.254)\end{array}$ & $\begin{array}{c}-0.999^{* *} \\
(0.405)\end{array}$ & $\begin{array}{c}-1.858^{* * *} \\
(0.486)\end{array}$ & $\begin{array}{c}-3.967^{* * *} \\
(0.470)\end{array}$ & $\begin{array}{c}-1.759^{* * *} \\
(0.269)\end{array}$ & $\begin{array}{c}-1.833^{* * *} \\
(0.433)\end{array}$ & $\begin{array}{c}-2.152^{* * *} \\
(0.461)\end{array}$ & $\begin{array}{c}-3.833^{* * *} \\
(0.453)\end{array}$ \\
\hline$D T I_{i, t-1}$ & $\begin{array}{c}-0.146^{* * *} \\
(0.022)\end{array}$ & $\begin{array}{c}-0.600^{* * * *} \\
(0.016)\end{array}$ & $\begin{array}{c}-0.503^{* * *} \\
(0.012)\end{array}$ & $\begin{array}{c}-0.102^{* * *} \\
(0.008)\end{array}$ & $\begin{array}{c}-0.136^{* * *} \\
(0.021)\end{array}$ & $\begin{array}{c}-0.628^{* * *} \\
(0.017)\end{array}$ & $\begin{array}{c}-0.492^{* * *} \\
(0.012)\end{array}$ & $\begin{array}{c}-0.102^{* * *} \\
(0.007)\end{array}$ \\
\hline Year fixed effects & Yes & Yes & Yes & Yes & Yes & Yes & Yes & Yes \\
\hline Household fixed effects & Yes & Yes & Yes & Yes & Yes & Yes & Yes & Yes \\
\hline Observations & 57,216 & 38,262 & 44,270 & 45,930 & 53,584 & 30,756 & 47,080 & 48,982 \\
\hline$R^{2}$ & 0.033 & 0.076 & 0.073 & 0.023 & 0.034 & 0.096 & 0.071 & 0.023 \\
\hline
\end{tabular}

Notes: All specifications include a fourth polynomial in age, household size, and growth in household size. Standard errors in parenthesis are clustered at the household level. ${ }^{*}{ }^{* *}$ and ${ }^{* * *}$ denotes significance at the 10 percent, 5 percent and 1 percent level, respectively. 
Table 14: Reduced Form Estimates Using $\Delta \widetilde{r}_{i, t}-$ Additional controls

\begin{tabular}{|c|c|c|c|c|c|c|}
\hline & \multicolumn{2}{|c|}{ Low } & \multicolumn{2}{|c|}{ Medium } & \multicolumn{2}{|c|}{ High } \\
\hline & (1) & (2) & (3) & $(4)$ & (5) & (6) \\
\hline$\Delta \widetilde{r}_{i, t}$ & $\begin{array}{c}-1.194^{* * * *} \\
(0.350)\end{array}$ & $\begin{array}{c}-1.851^{* * * *} \\
(0.446)\end{array}$ & $\begin{array}{c}-1.951^{* * *} \\
(0.454)\end{array}$ & $\begin{array}{c}-3.338^{* * *} \\
(0.569)\end{array}$ & $\begin{array}{c}-3.779^{* * *} \\
(0.454)\end{array}$ & $\begin{array}{c}-6.498^{* * *} \\
(0.656)\end{array}$ \\
\hline$L T V_{i, t-1}$ & $\begin{array}{c}-0.556^{* * * *} \\
(0.014)\end{array}$ & $\begin{array}{c}-0.678^{* * * *} \\
(0.018)\end{array}$ & $\begin{array}{c}-0.482^{* * *} \\
(0.011)\end{array}$ & $\begin{array}{c}-0.581^{* * *} \\
(0.014)\end{array}$ & $\begin{array}{c}-0.102^{* * *} \\
(0.007)\end{array}$ & $\begin{array}{c}-0.157^{* * *} \\
(0.011)\end{array}$ \\
\hline$\Delta \log$ housevalue $_{i, t}$ & $\begin{array}{l}-0.004 \\
(0.003)\end{array}$ & $\begin{array}{l}-0.001 \\
(0.005)\end{array}$ & $\begin{array}{l}-0.013 \\
(0.009)\end{array}$ & $\begin{array}{l}-0.013 \\
(0.011)\end{array}$ & $\begin{array}{c}0.008 \\
(0.013)\end{array}$ & $\begin{array}{c}0.002 \\
(0.015)\end{array}$ \\
\hline$\Delta \log c_{i, t-1}$ & & $\begin{array}{c}-0.322^{* * *} \\
(0.008)\end{array}$ & & $\begin{array}{c}-0.350^{* * * *} \\
(0.008)\end{array}$ & & $\begin{array}{c}-0.350^{* * *} \\
(0.007)\end{array}$ \\
\hline$\Delta \log y_{i, t-1}$ & & $\begin{array}{c}-0.077^{* * *} \\
(0.020)\end{array}$ & & $\begin{array}{c}-0.195^{* * * *} \\
(0.022)\end{array}$ & & $\begin{array}{c}-0.107^{* * *} \\
(0.022)\end{array}$ \\
\hline Year fixed effects & Yes & Yes & Yes & Yes & Yes & Yes \\
\hline Household fixed effects & Yes & Yes & Yes & Yes & Yes & Yes \\
\hline Observations & 49,247 & 36,931 & 49,248 & 37,305 & 49,247 & 36,287 \\
\hline$R^{2}$ & 0.067 & 0.253 & 0.067 & 0.302 & 0.023 & 0.250 \\
\hline
\end{tabular}

Notes: All specifications include a fourth polynomial in age, household size, and growth in household size. Standard errors in parenthesis are clustered at the household level. **** and *** denotes significance at the 10 percent, 5 percent and 1 percent level, respectively.

Table 15: Cross-Sectional OLS and Reduced Form Estimates

\begin{tabular}{ccccccccc}
\hline \hline & \multicolumn{3}{c}{ Reduced Form $\left(\Delta \widetilde{r}_{i, t}\right)$} & & \multicolumn{3}{c}{ OLS } \\
\cline { 2 - 5 } \cline { 7 - 8 } & Low & Medium & High & & Low & Medium & High \\
& $(1)$ & $(2)$ & $(3)$ & & $(4)$ & $(5)$ & $(6)$ \\
\hline 2002 & $16.404^{* * *}$ & 10.878 & 4.142 & & $-2.372^{* * *}$ & $-9.001^{* * *}$ & $-10.710^{* * *}$ \\
& $(6.440)$ & $(9.478)$ & $(11.499)$ & & $(0.129)$ & $(0.432)$ & $(0.681)$ \\
2003 & $-4.330^{* * *}$ & $-5.892^{* * *}$ & $-6.495^{* * *}$ & & $-2.225^{* * *}$ & $-8.467^{* * *}$ & $-9.590^{* * *}$ \\
& $(0.671)$ & $(0.898)$ & $(1.073)$ & & $(0.137)$ & $(0.533)$ & $(0.719)$ \\
2004 & $-3.547^{* * *}$ & $-5.817^{* * *}$ & $-5.945^{* * *}$ & $-2.376^{* * *}$ & $-8.961^{* * *}$ & $-9.918^{* * * *}$ \\
& $(0.580)$ & $(0.732)$ & $(0.843)$ & & $(0.141)$ & $(0.401)$ & $(0.680)$ \\
2005 & $-4.375^{* * *}$ & $-5.386^{* * *}$ & 0.337 & & $-2.765^{* * *}$ & $-7.844^{* * *}$ & $-6.647^{* * *}$ \\
& $(1.245)$ & $(1.527)$ & $(1.522)$ & & $(0.142)$ & $(0.469)$ & $(0.650)$ \\
2006 & $-4.772^{* * *}$ & $-6.875^{* * *}$ & $-8.369^{* * *}$ & $-2.207^{* * *}$ & $-6.008^{* * *}$ & $-4.747^{* * *}$ \\
& $(1.248)$ & $(1.489)$ & $(1.414)$ & & $(0.162)$ & $(0.431)$ & $(0.477)$ \\
2007 & $-3.341^{* * *}$ & $-3.413^{* * *}$ & $-4.122^{* * *}$ & $-2.282^{* * *}$ & $-7.666^{* * *}$ & $-9.769^{* * * *}$ \\
& $(0.548)$ & $(0.628)$ & $(0.600)$ & $(0.149)$ & $(0.613)$ & $(0.786)$ \\
\hline
\end{tabular}

Notes: All specifications include a fourth polynomial in age, household size, and growth in household size. Standard errors in parenthesis are clustered at the household level. ${ }^{*}$, ${ }^{* *}$ and ${ }^{* * *}$ denotes significance at the 10 percent, 5 percent and 1 percent level, respectively. 
Table 16: Pooled samples: OLS Estimates of Changes in Household Interest Rates, $\Delta r_{i, t}^{d}$

\begin{tabular}{lcccc}
\hline \hline & $(1)$ & $(2)$ & $(3)$ & $(4)$ \\
\hline & & & & \\
$\Delta r_{i, t}^{d} * D_{i}($ Renter $)$ & $-1.333^{* * *}$ & $-1.368^{* * *}$ & $-1.335^{* * *}$ & $-1.369^{* * *}$ \\
$\Delta r_{i, t}^{d} * D_{i}$ (Low) & $(0.028)$ & $(0.033)$ & $(0.028)$ & $(0.034)$ \\
& $-2.412^{* * *}$ & $-2.437^{* * *}$ & $-2.406^{* * *}$ & $-2.218^{* * *}$ \\
$\Delta r_{i, t}^{d} * D_{i}$ (Medium) & $(0.066)$ & $(0.076)$ & $(0.066)$ & $(0.074)$ \\
& $-7.692^{* * *}$ & $-7.445^{* * *}$ & $-7.678^{* * *}$ & $-7.051^{* * *}$ \\
$\Delta r_{i, t}^{d} * D_{i}($ High $)$ & $(0.204)$ & $(0.211)$ & $(0.204)$ & $(0.208)$ \\
& $-7.465^{* * *}$ & $-6.493^{* * *}$ & $-7.477^{* * *}$ & $-6.577^{* * *}$ \\
& $(0.323)$ & $(0.344)$ & $(0.324)$ & $(0.347)$ \\
Covariates interacted with group & & & & \\
Household fixed effects & No & No & Yes & Yes \\
Observations & No & Yes & No & Yes \\
$R^{2}$ & 210,624 & 210,624 & 210,624 & 210,624 \\
\hline
\end{tabular}

Notes: Each regression pools renters and the three groups of homeowners with debt. Households with no debt are excluded. All specifications include a fourth polynomial in age, household size, and growth in household size. Column (3) and (4) allow the household-specific covariates to have different effects for each of the four groups. Year effects are common to all four groups. Standard errors in parenthesis are clustered at the household level. ${ }^{*}{ }^{* *}$ and ${ }^{* * *}$ denotes significance at the 10 percent, 5 percent and 1 percent level, respectively. 
Table 17: Pooled samples: Reduced form and IV estimates based on $\Delta \widetilde{r}_{i, t}$

\begin{tabular}{|c|c|c|c|c|c|c|c|c|}
\hline & \multicolumn{4}{|c|}{ Reduced Form $\left(\Delta \widetilde{r}_{i, t}\right)$} & \multicolumn{4}{|c|}{ IV estimates } \\
\hline & $(1)$ & $(2)$ & (3) & (4) & (5) & $(6)$ & $(7)$ & $(8)$ \\
\hline$\Delta \widetilde{r}_{i, t} * D_{i}($ Renter $)$ & $\begin{array}{c}-2.403^{* * *} \\
(0.176)\end{array}$ & $\begin{array}{c}-1.775^{* * *} \\
(0.209)\end{array}$ & $\begin{array}{c}-2.369^{* * *} \\
(0.176)\end{array}$ & $\begin{array}{c}-1.634^{* * *} \\
(0.229)\end{array}$ & & & & \\
\hline$\Delta \widetilde{r}_{i, t} * D_{i}($ Low $)$ & $\begin{array}{c}-4.162^{* * *} \\
(0.223)\end{array}$ & $\begin{array}{c}-3.513^{* * *} \\
(0.271)\end{array}$ & $\begin{array}{c}-4.168^{* * *} \\
(0.223)\end{array}$ & $\begin{array}{c}-3.250^{* * *} \\
(0.281)\end{array}$ & & & & \\
\hline$\Delta \widetilde{r}_{i, t} * D_{i}($ Medium $)$ & $\begin{array}{c}-4.119^{* * *} \\
(0.235)\end{array}$ & $\begin{array}{c}-3.106^{* * *} \\
(0.278)\end{array}$ & $\begin{array}{c}-4.083^{* * *} \\
(0.235)\end{array}$ & $\begin{array}{c}-2.585^{* * *} \\
(0.290)\end{array}$ & & & & \\
\hline$\Delta \widetilde{r}_{i, t} * D_{i}($ High $)$ & $\begin{array}{c}-3.982^{* * *} \\
(0.246)\end{array}$ & $\begin{array}{c}-2.041^{* * *} \\
(0.304)\end{array}$ & $\begin{array}{c}-4.029^{* * *} \\
(0.246)\end{array}$ & $\begin{array}{c}-1.997^{* * *} \\
(0.313)\end{array}$ & & & & \\
\hline$\Delta r_{i, t}^{d} * D_{i}($ Renter $)$ & & & & & $\begin{array}{c}-1.086^{* * *} \\
(0.103)\end{array}$ & $\begin{array}{c}-0.963^{* * *} \\
(0.127)\end{array}$ & $\begin{array}{c}-1.082^{* * *} \\
(0.103)\end{array}$ & $\begin{array}{c}-0.969^{* * *} \\
(0.138)\end{array}$ \\
\hline$\Delta r_{i, t}^{d} * D_{i}(\mathrm{Low})$ & & & & & $\begin{array}{c}-3.134^{* * *} \\
(0.186)\end{array}$ & $\begin{array}{c}-3.082^{* * *} \\
(0.220)\end{array}$ & $\begin{array}{c}-3.141^{* * *} \\
(0.186)\end{array}$ & $\begin{array}{c}-2.892^{* * *} \\
(0.229)\end{array}$ \\
\hline$\Delta r_{i, t}^{d} * D_{i}($ Medium $)$ & & & & & $\begin{array}{c}-5.515^{* * *} \\
(0.341)\end{array}$ & $\begin{array}{c}-4.730^{* * *} \\
(0.376)\end{array}$ & $\begin{array}{c}-5.480^{* * *} \\
(0.341)\end{array}$ & $\begin{array}{c}-3.965^{* * *} \\
(0.388)\end{array}$ \\
\hline$\Delta r_{i, t}^{d} * D_{i}($ High $)$ & & & & & $\begin{array}{c}-5.903^{* * *} \\
(0.403)\end{array}$ & $\begin{array}{c}-3.731^{* * *} \\
(0.453)\end{array}$ & $\begin{array}{c}-5.953^{* * *} \\
(0.403)\end{array}$ & $\begin{array}{c}-3.372^{* * *} \\
(0.459)\end{array}$ \\
\hline Covariates interacted with group & No & No & Yes & Yes & No & No & Yes & Yes \\
\hline Household fixed effects & No & Yes & No & Yes & No & Yes & No & Yes \\
\hline Observations & 211,635 & 211,635 & 211,635 & 211,635 & 202,485 & 201,421 & 202,485 & 201,421 \\
\hline$R^{2}$ & 0.012 & 0.035 & 0.013 & 0.043 & 0.062 & 0.077 & 0.062 & 0.081 \\
\hline
\end{tabular}

Notes: Each regression pools renters and the three groups of homeowners with debt. Households with no debt are excluded. All specifications include a fourth polynomial in age, household size, and growth in household size. Column (1) to (4) report reduced form estimates whereas column (5) to (8) reports instrument the individiual rates with changes in the repo rate. Column (3), (4), (7) and (8) allow the household-specific covariates to have different effects for each of the four groups. Year effects are common to all four groups. Standard errors in parenthesis are clustered at the household level. ${ }^{*}, * *$ and ${ }^{* * *}$ denotes significance at the 10 percent, 5 percent and 1 percent level, respectively. 
Table 18: Pooled samples: Reduced form and IV estimates based on $\widetilde{M P S}_{i, t}$

\begin{tabular}{|c|c|c|c|c|c|c|c|c|}
\hline & \multicolumn{4}{|c|}{ Reduced Form $\left(\widehat{M P S_{i, t}}\right)$} & \multicolumn{4}{|c|}{ IV estimates } \\
\hline & $(1)$ & $(2)$ & (3) & $(4)$ & (5) & (6) & $(7)$ & $(8)$ \\
\hline$\widetilde{M P S}_{i, t} * D_{i}($ Renter $)$ & $\begin{array}{c}-11.112^{* * *} \\
(1.053)\end{array}$ & $\begin{array}{c}-7.263^{* * *} \\
(1.285)\end{array}$ & $\begin{array}{c}-10.938^{* * *} \\
(1.054)\end{array}$ & $\begin{array}{l}-6.398^{* * *} \\
(1.420)\end{array}$ & & & & \\
\hline$\widehat{M P S}_{i, t} * D_{i}($ Low $)$ & $\begin{array}{c}-20.561^{* * * *} \\
(1.351)\end{array}$ & $\begin{array}{c}-15.908^{* * *} \\
(1.682)\end{array}$ & $\begin{array}{c}-20.691^{* * *} \\
(1.356)\end{array}$ & $\begin{array}{c}-14.568^{* * *} \\
(1.774)\end{array}$ & & & & \\
\hline$\widetilde{M P S}_{i, t} * D_{i}($ Medium $)$ & $\begin{array}{c}-20.605^{* * *} \\
(1.436)\end{array}$ & $\begin{array}{c}-15.790^{* * *} \\
(1.710)\end{array}$ & $\begin{array}{c}-20.438^{* * *} \\
(1.438)\end{array}$ & $\begin{array}{c}-13.389^{* * *} \\
(1.824)\end{array}$ & & & & \\
\hline$\widehat{M P S}_{i, t} * D_{i}(\mathrm{High})$ & $\begin{array}{c}-20.471^{* * *} \\
(1.508)\end{array}$ & $\begin{array}{c}-11.223^{* * *} \\
(1.841)\end{array}$ & $\begin{array}{c}-20.856^{* * *} \\
(1.510)\end{array}$ & $\begin{array}{c}-10.278^{* * *} \\
(1.950)\end{array}$ & & & & \\
\hline$\Delta r_{i, t}^{d} * D_{i}($ Renter $)$ & & & & & $\begin{array}{c}-0.953^{* * *} \\
(0.124)\end{array}$ & $\begin{array}{c}-0.808^{* * *} \\
(0.175)\end{array}$ & $\begin{array}{c}-0.950^{* * *} \\
(0.124)\end{array}$ & $\begin{array}{c}-0.821^{* * *} \\
(0.194)\end{array}$ \\
\hline$\Delta r_{i, t}^{d} * D_{i}($ Low $)$ & & & & & $\begin{array}{l}-3.083^{* * *} \\
(0.231)\end{array}$ & $\begin{array}{c}-2.914^{* * *} \\
(0.311)\end{array}$ & $\begin{array}{c}-3.103^{* * *} \\
(0.230)\end{array}$ & $\begin{array}{c}-2.683^{* * * *} \\
(0.325)\end{array}$ \\
\hline$\Delta r_{i, t}^{d} * D_{i}($ Medium $)$ & & & & & $\begin{array}{c}-5.274^{* * *} \\
(0.412)\end{array}$ & $\begin{array}{c}-4.741^{* * *} \\
(0.495)\end{array}$ & $\begin{array}{c}-5.240^{* * *} \\
(0.413)\end{array}$ & $\begin{array}{c}-3.923^{* * *} \\
(0.512)\end{array}$ \\
\hline$\Delta r_{i, t}^{d} * D_{i}($ High $)$ & & & & & $\begin{array}{c}-5.899^{* * *} \\
(0.482)\end{array}$ & $\begin{array}{c}-3.942^{* * *} \\
(0.583)\end{array}$ & $\begin{array}{c}-5.987^{* * *} \\
(0.483)\end{array}$ & $\begin{array}{c}-3.277^{* * * *} \\
(0.604)\end{array}$ \\
\hline Covariates interacted with group & No & No & Yes & Yes & No & No & Yes & Yes \\
\hline Household fixed effects & No & Yes & No & Yes & No & Yes & No & Yes \\
\hline Observations & 211,635 & 211,635 & 211,635 & 211,635 & 202,485 & 201,421 & 202,485 & 201,421 \\
\hline$R^{2}$ & 0.011 & 0.034 & 0.012 & 0.043 & 0.061 & 0.077 & 0.062 & 0.081 \\
\hline
\end{tabular}

Notes: Each regression pools renters and the three groups of homeowners with debt. Households with no debt are excluded. All specifications include a fourth polynomial in age, household size, and growth in household size. Column (1) to (4) report reduced form estimates whereas column (5) to (8) reports instrument the individiual rates with monetary policy shocks. Column (3), (4), (7) and (8) allow the household-specific covariates to have different effects for each of the four groups. Year effects are common to all four groups. Standard errors in parenthesis are clustered at the household level. * ${ }^{* *}$ and ${ }^{* * *}$ denotes significance at the 10 percent, 5 percent and 1 percent level, respectively. 
Figure 1: Repo Rate and Relative Consumption Growth

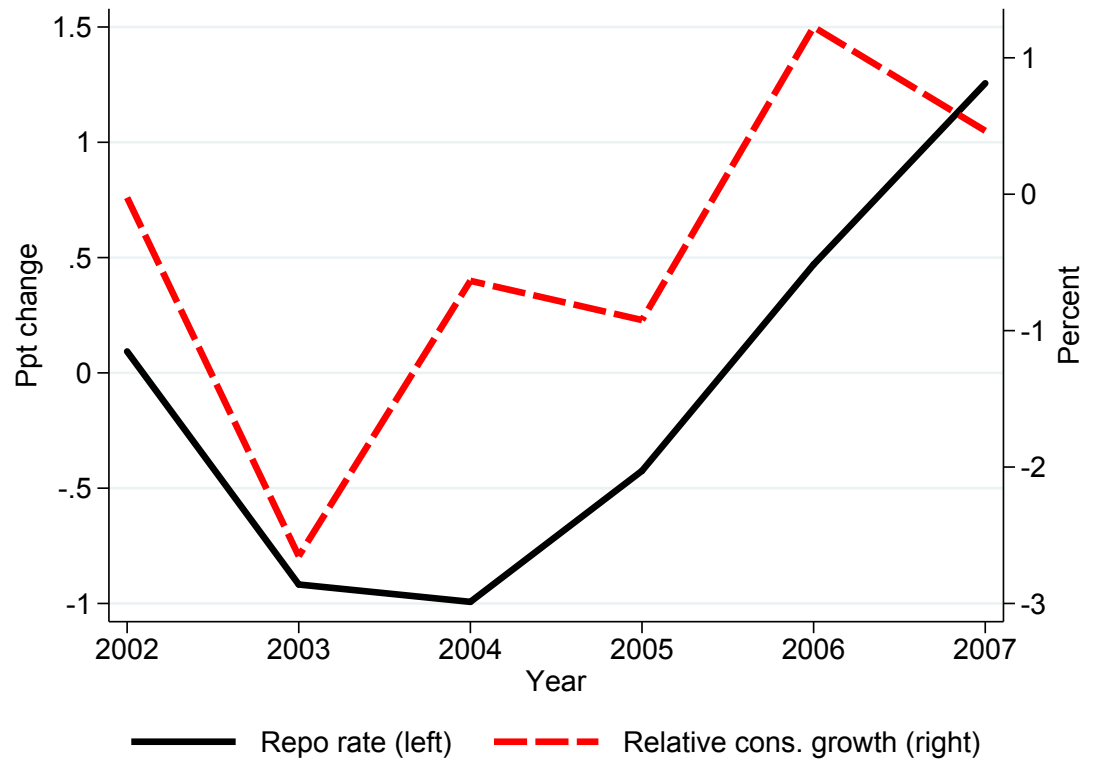

Note: Relative consumption growth is the difference between the median consumption growth across the total population of homeowners and the median consumption growth for homeowners with high debt and variable interest rate.

Figure 2: Income, Debt, and Consumption - Averages Across the Debt-to-Income Distribution

(a) Disposable income, debt and consumption

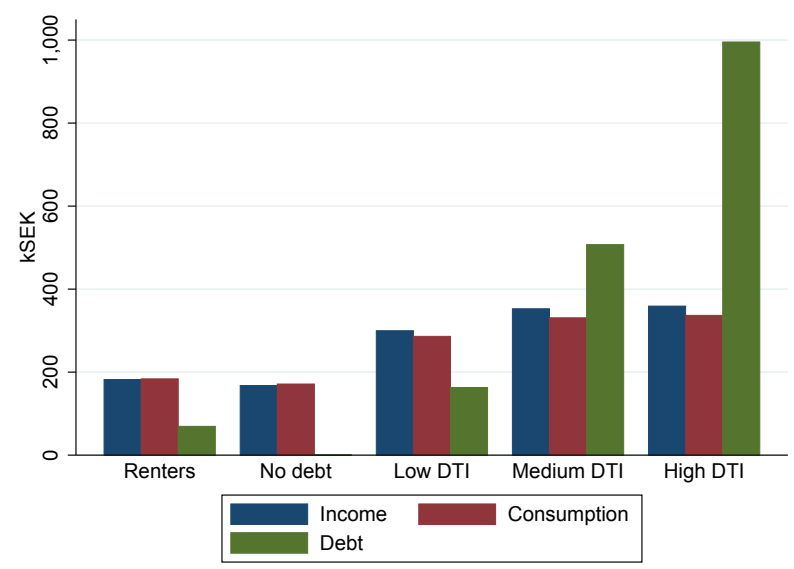

(b) Interest expenses

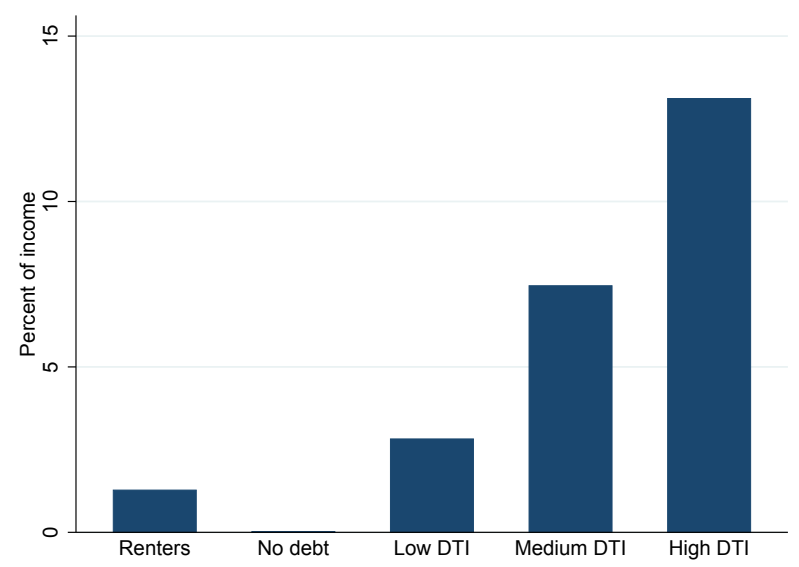


Figure 3: Household Wealth - Averages Across the Debt-to-Income Distribution

(a) Total, liquid, and illiquid assets

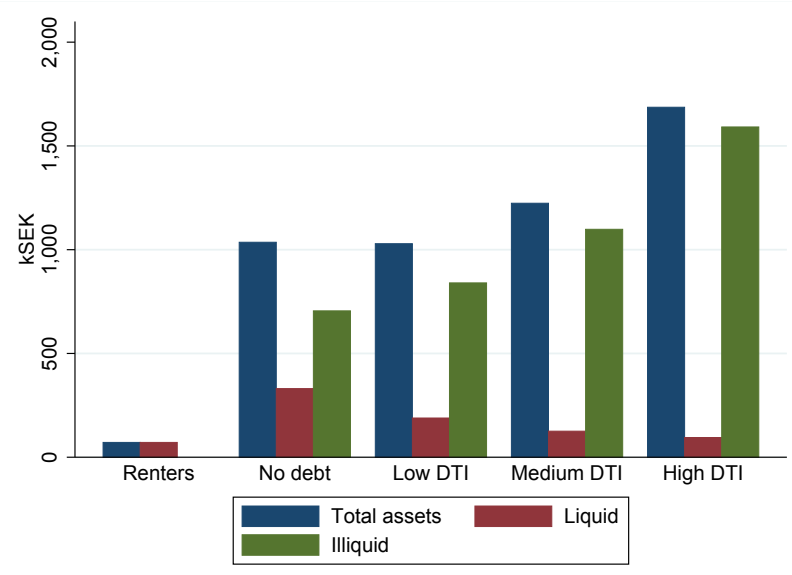

(c) Household net worth

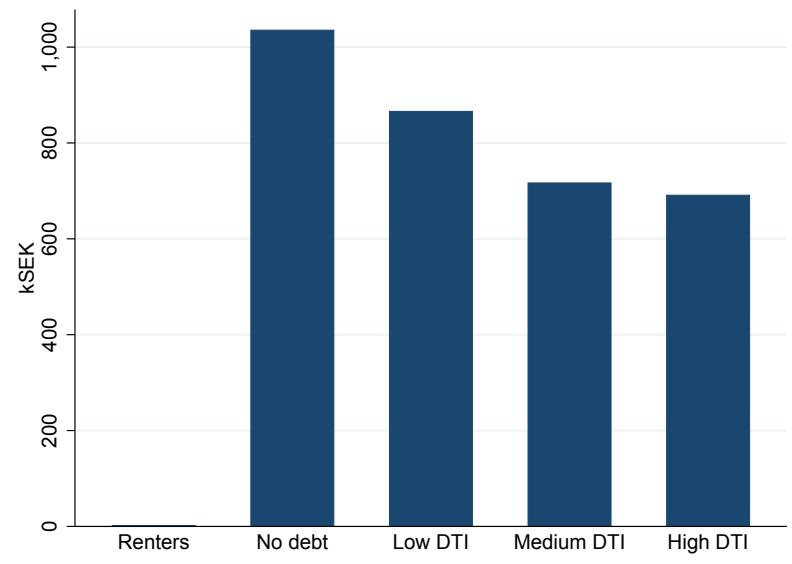

(b) Total, liquid, and illiquid assets

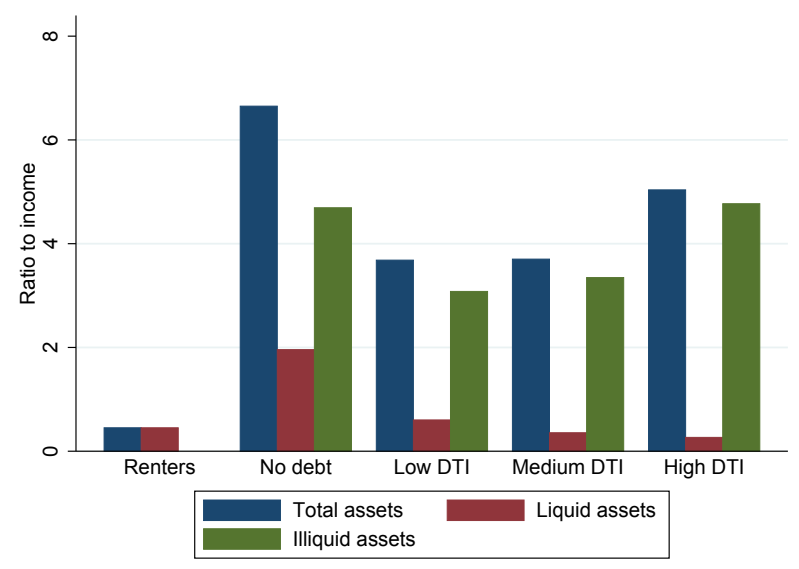

(d) Household net worth

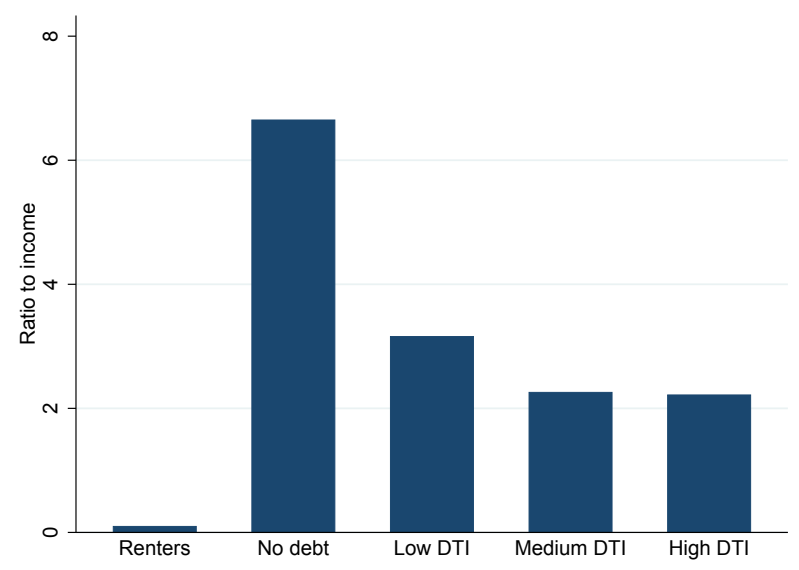


Figure 4: Household Debt and Liquid Asset Ratios - Mean and Median Across Income Deciles

(a) Mean, whole sample

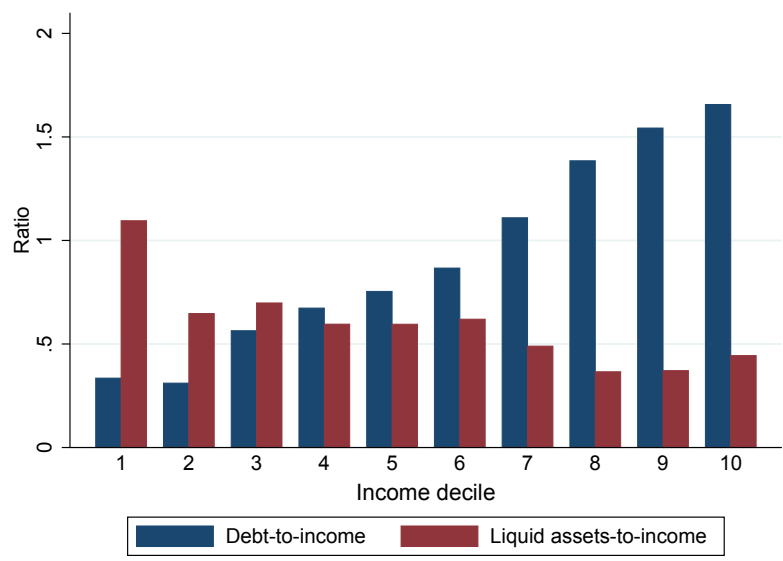

(c) Mean, homeowners

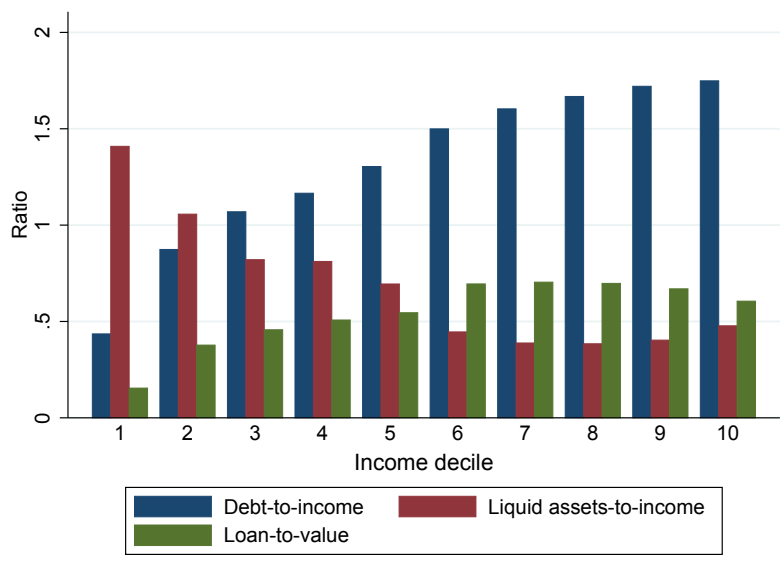

(e) Mean, homeowners with positive debt

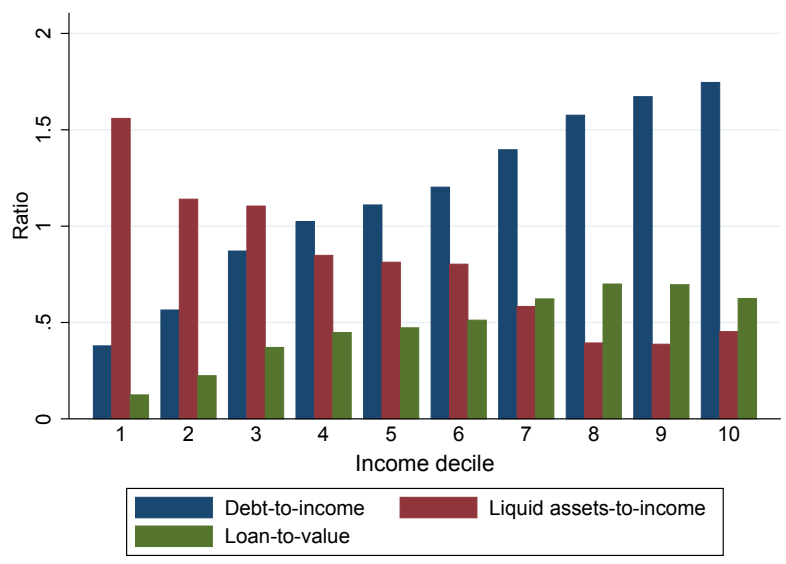

(b) Median, whole sample

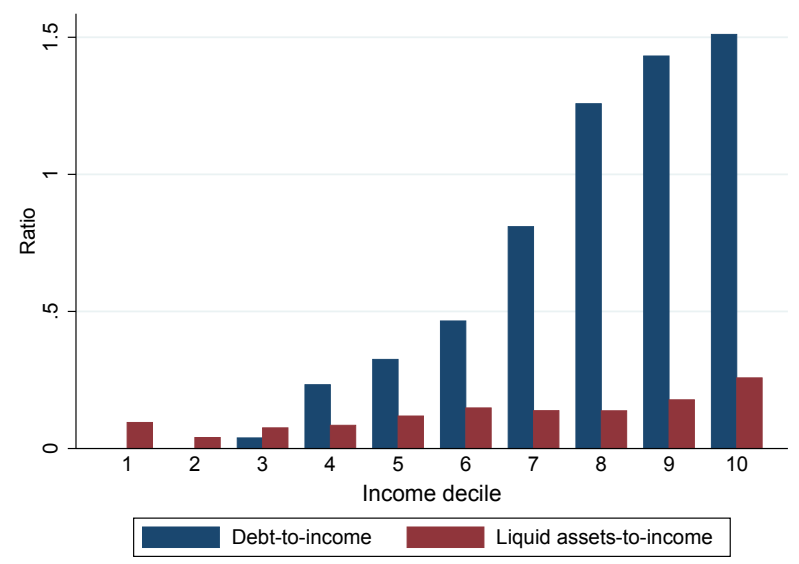

(d) Median, homeowners

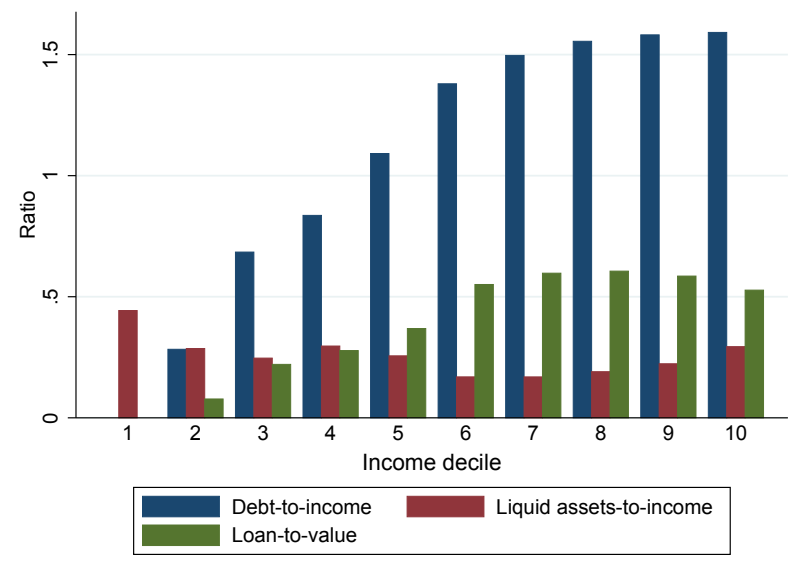

(f) Median, homeowners with positive debt

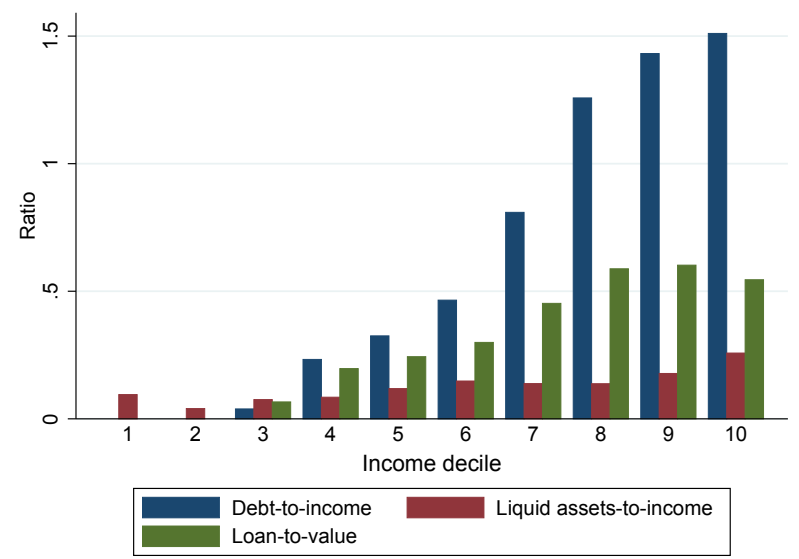


Figure 5: Household Debt, Wealth and Income - Mean and Median Across Income Deciles

(a) Mean, whole sample

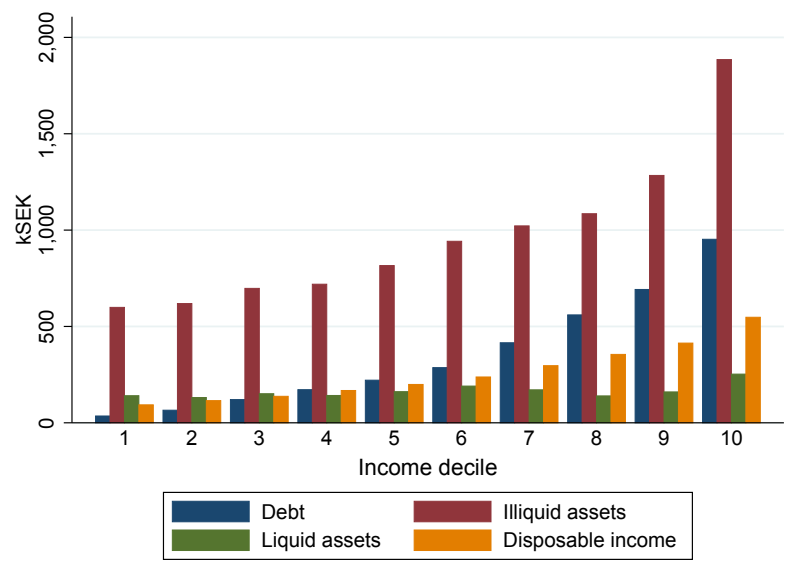

(c) Mean, homeowners

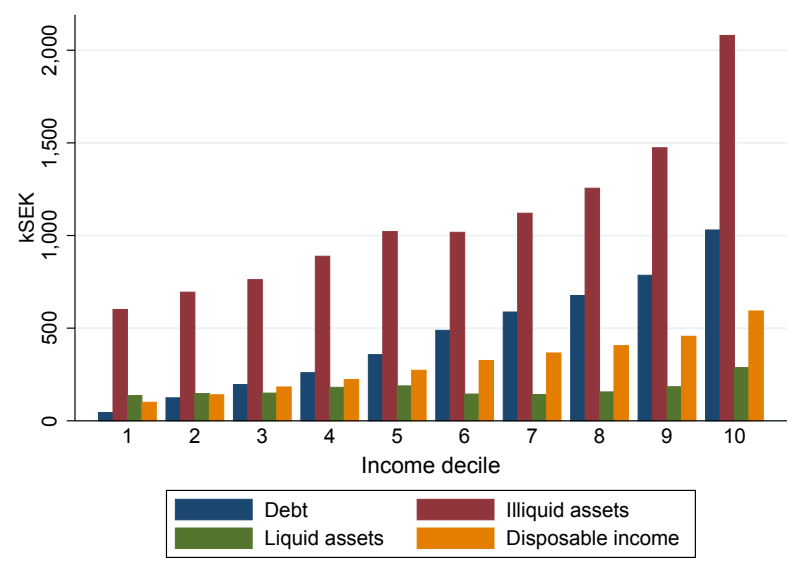

(e) Mean, homeowners with positive debt

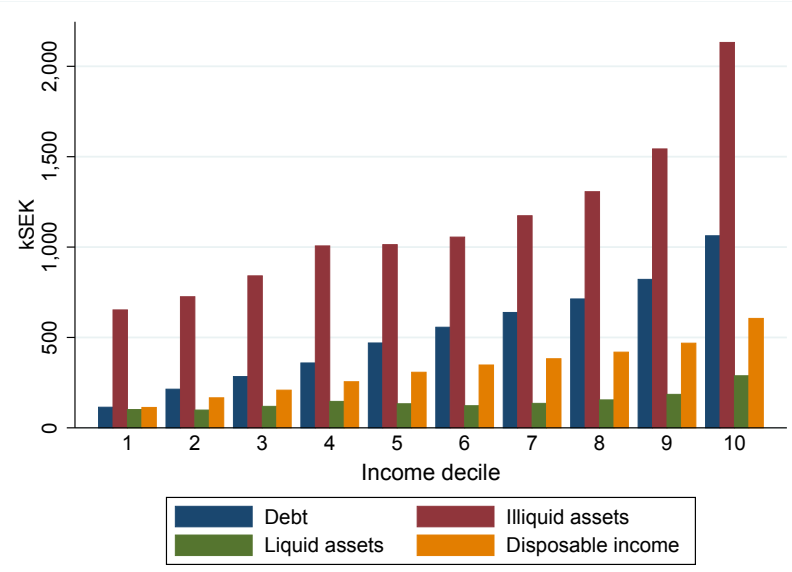

(b) Median, whole sample

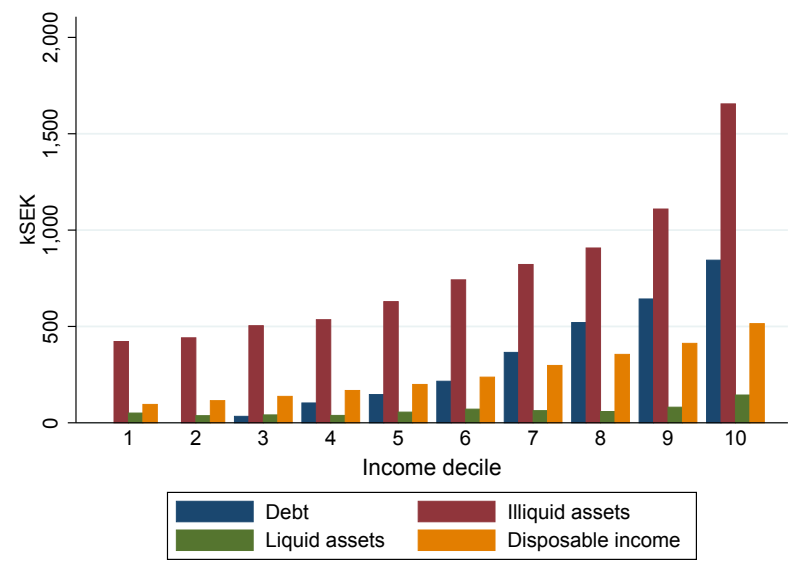

(d) Median, homeowners

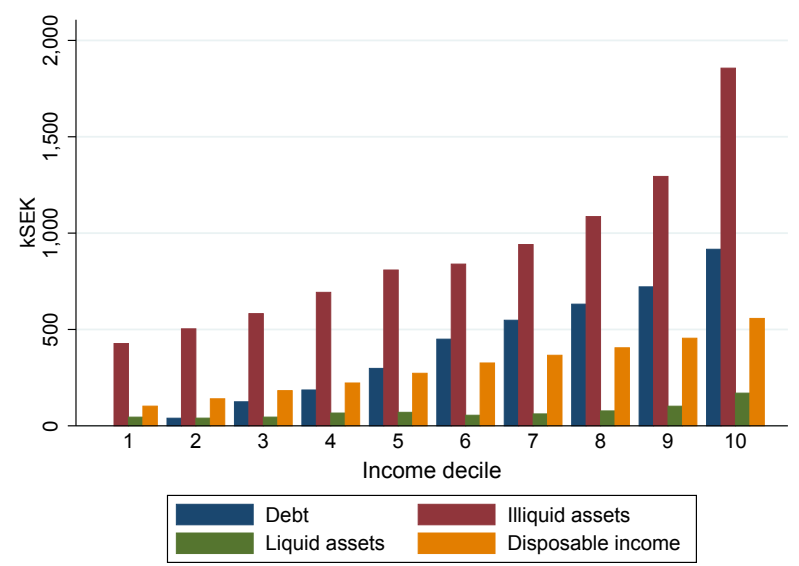

(f) Median, homeowners with positive debt

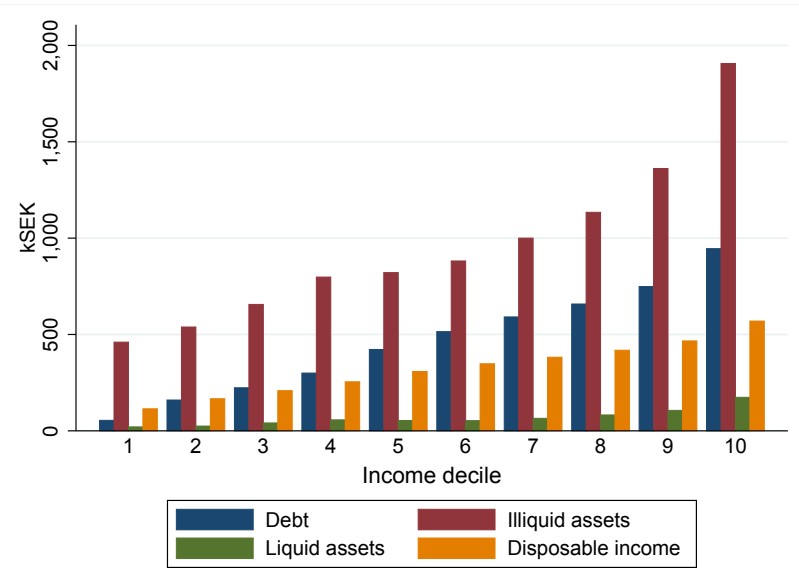


Figure 6: Household Debt and Liquid Asset Ratios - By Age Groups and Geographical Locations

(a) Mean

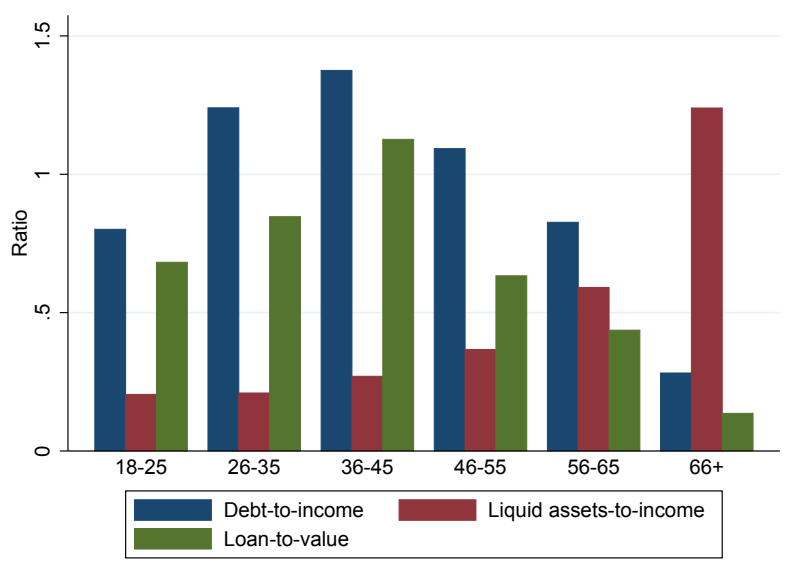

(c) Mean

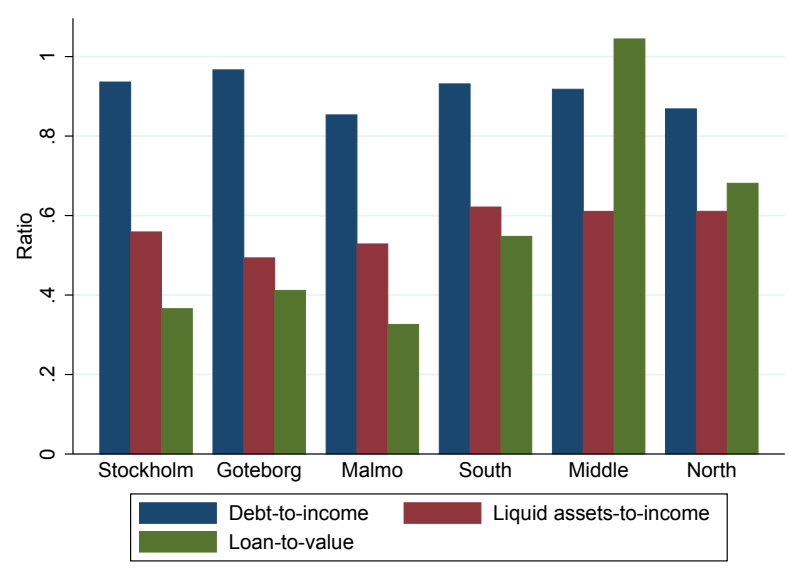

(b) Median

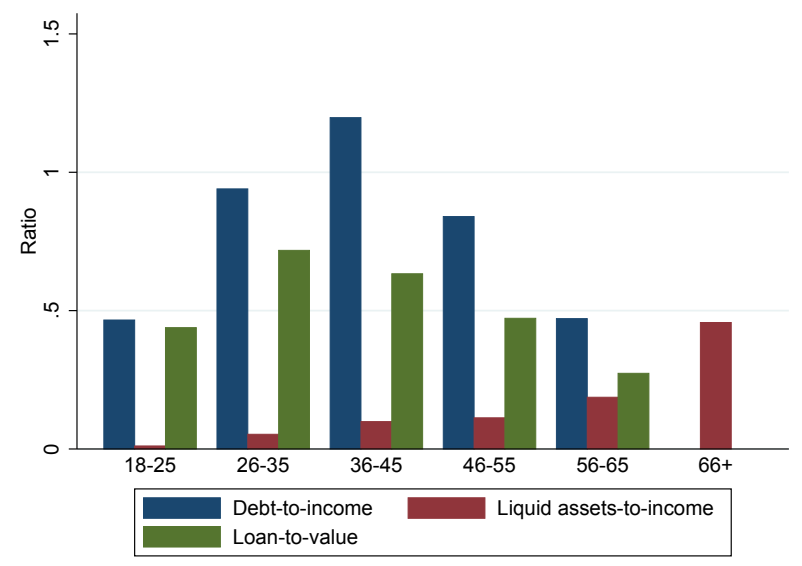

(d) Median

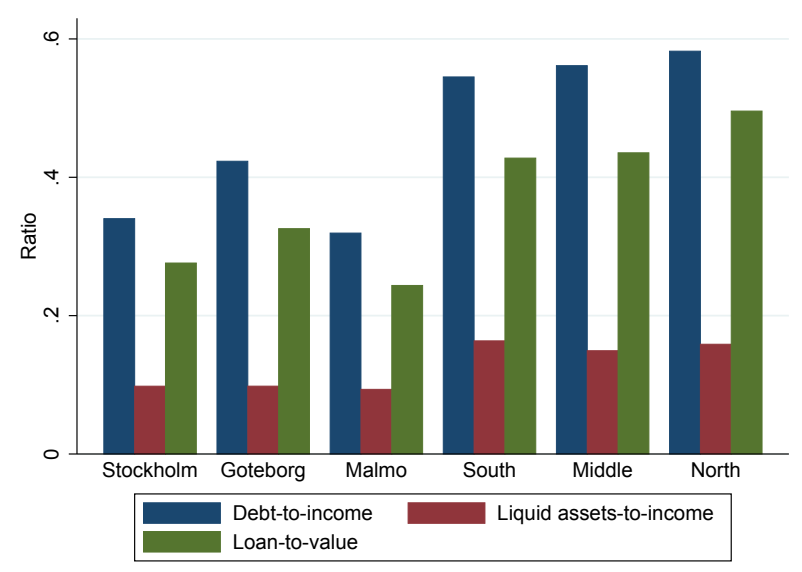


Figure 7: Shares of New Mortgages By Duration of Interest Rate Fixation

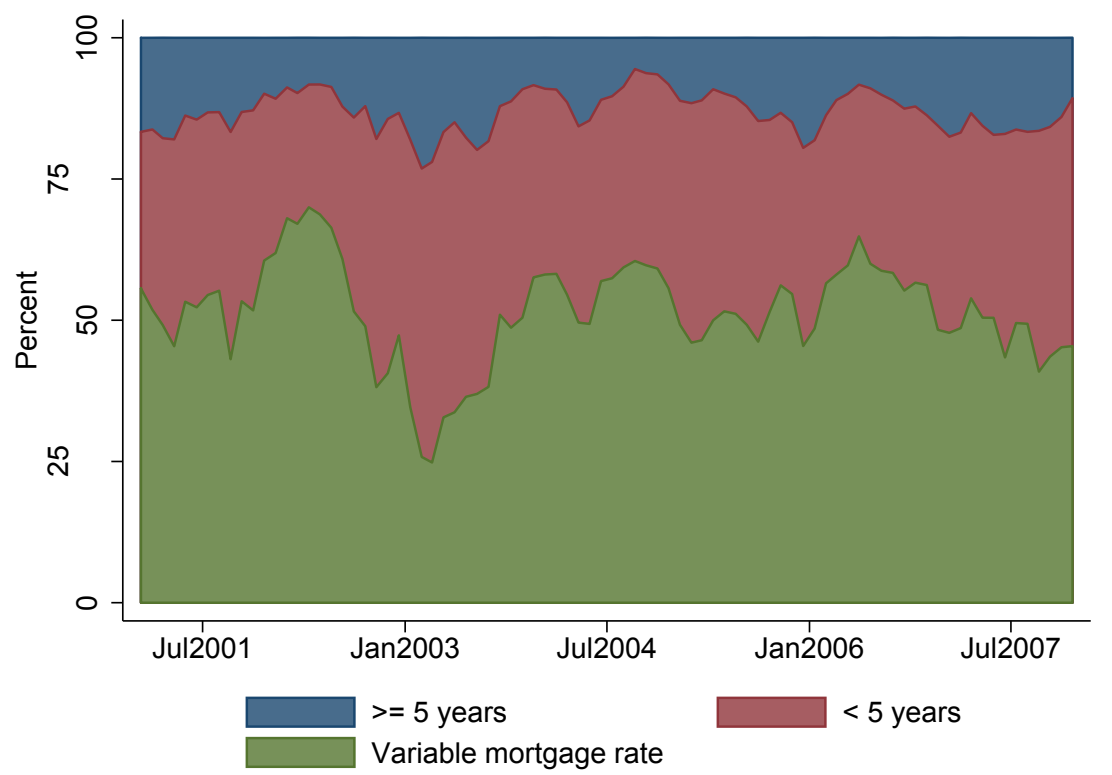

Note: Variable mortgage rate is defined as 3 months or shorter. The data source is Figure A18 in Riksbanken (2012).

Figure 8: Shares of the Stock of Mortgages By Duration of Interest Rate Fixation

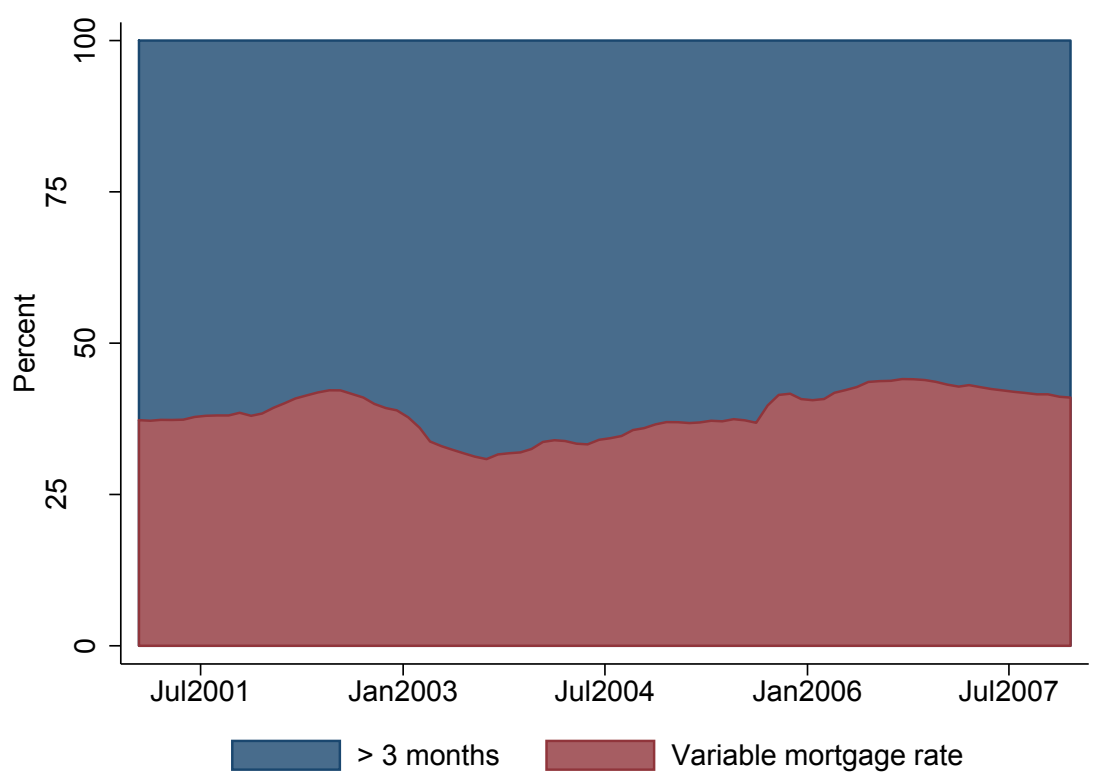

Note: Variable mortgage rate is defined as 3 months or shorter. The data source is Figure A30 in Riksbanken (2015). 
Figure 9: Repo Rate and the Average Household Interest Rate

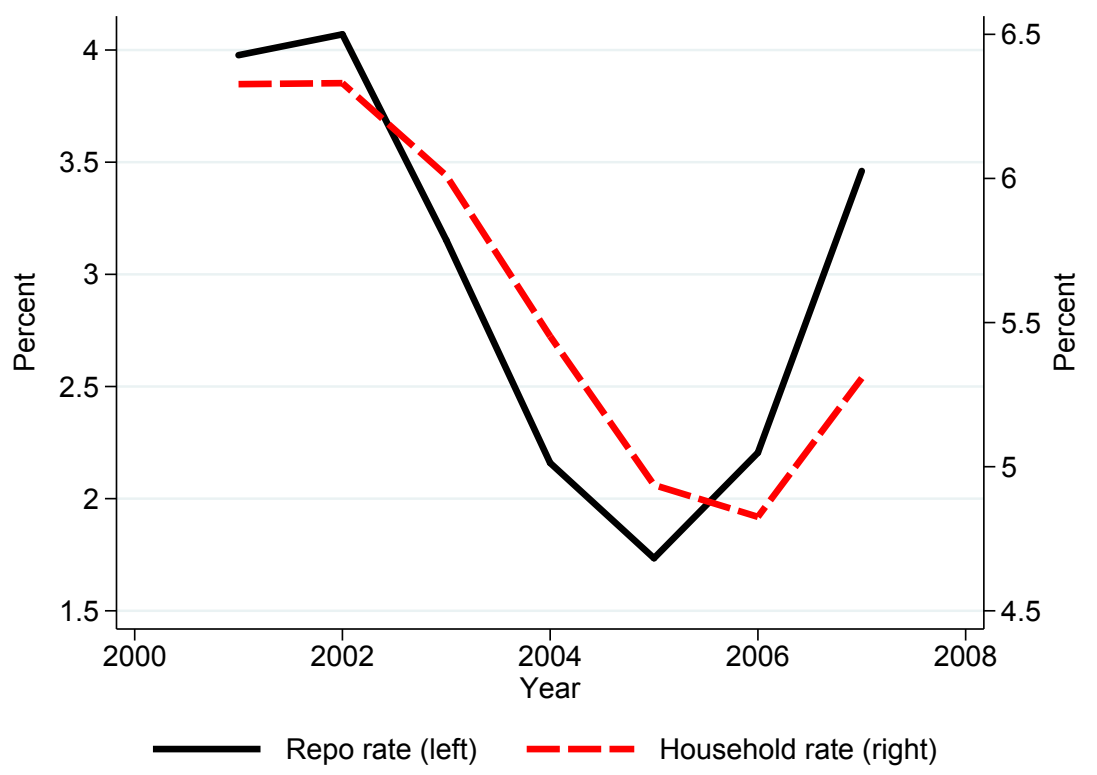

Figure 10: Repo Rate and Average Household Interest Rates By Interest Rate Variability

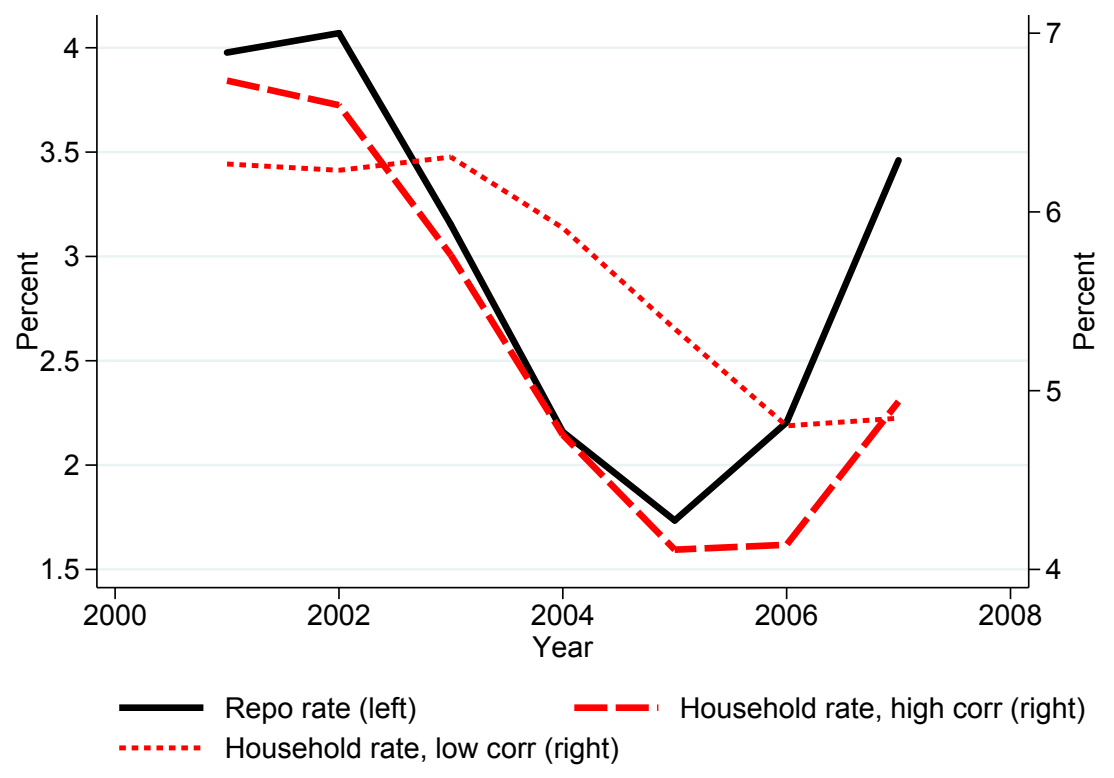


Figure 11: Distributions of Household Interest Rate Variability and Household Interest Rates
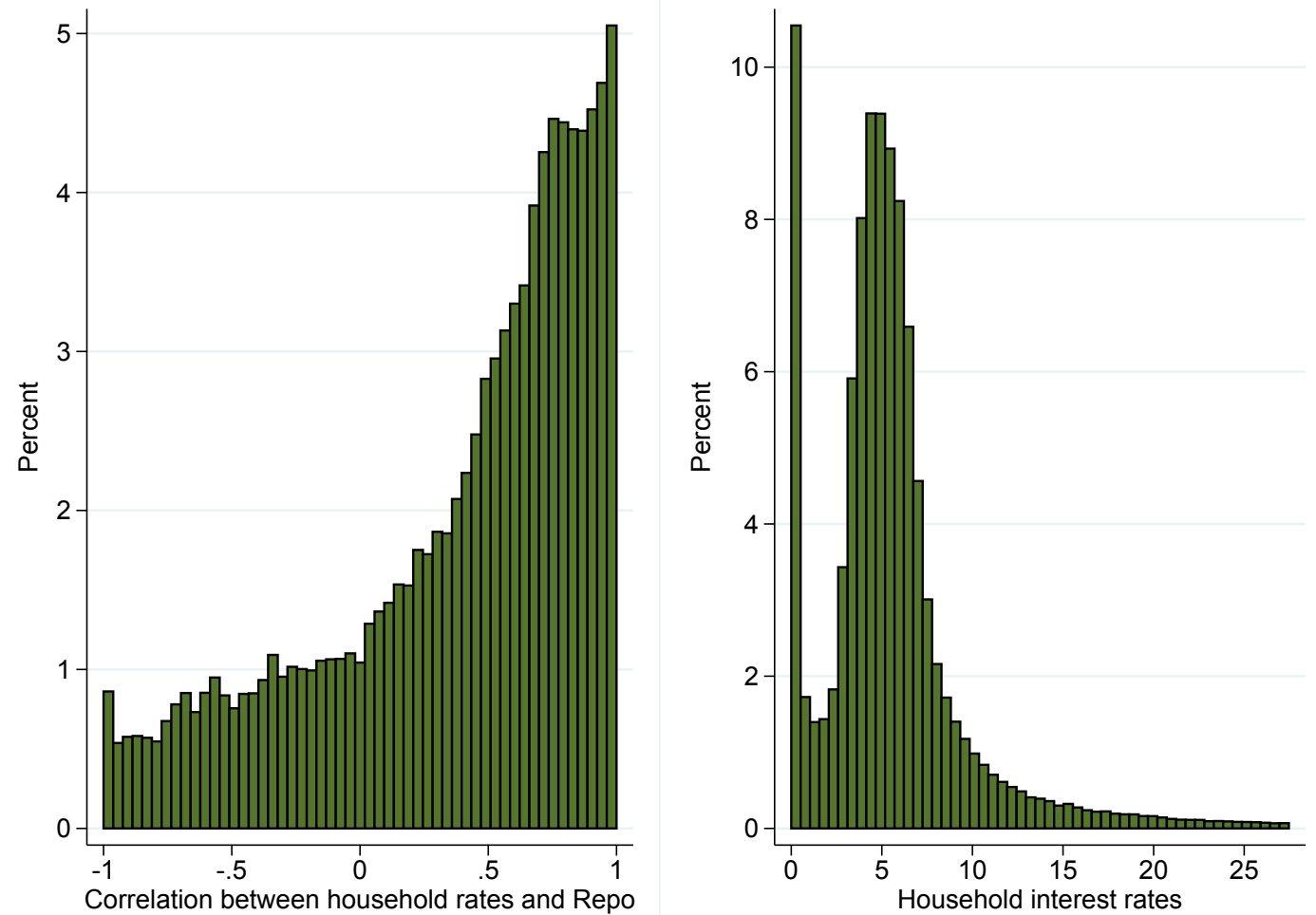

Figure 12: Change in the Repo Rate and Estimated Monetary Policy Shocks (MPS)

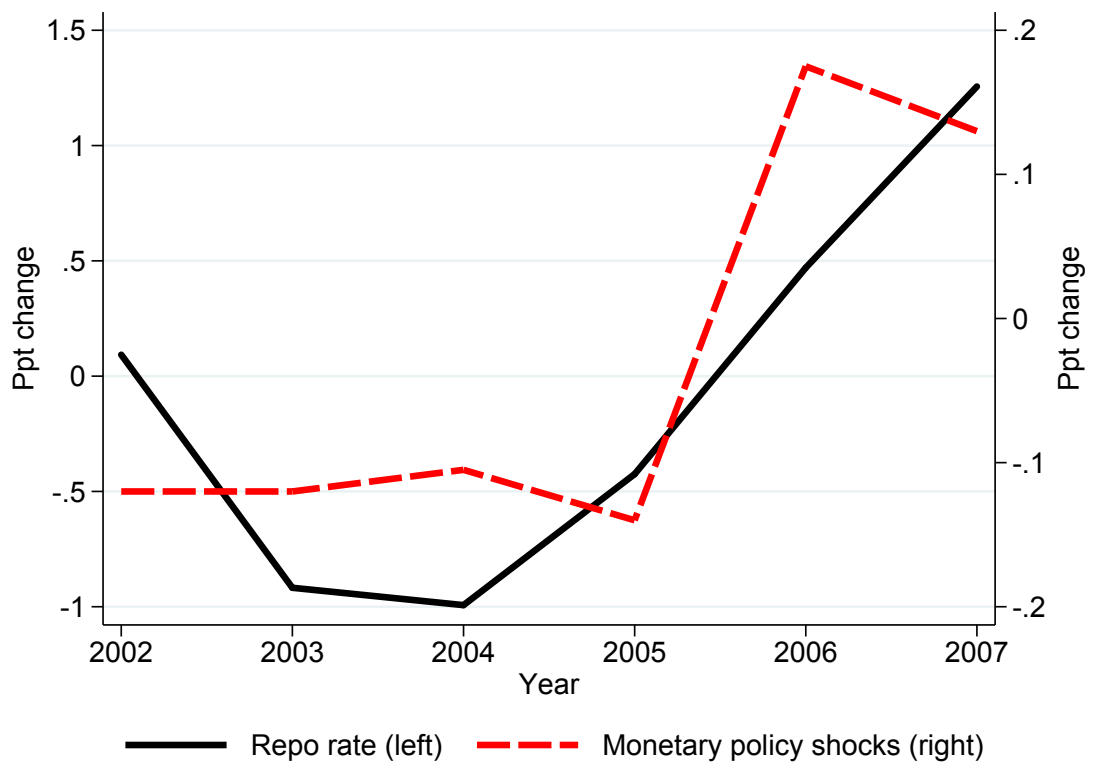

